Published in final edited form as:

Small. 2019 June ; 15(25): e1901397. doi:10.1002/smll.201901397.

\title{
Highly Porous Microcarriers for Minimally Invasive in situ Skeletal Muscle Cell Delivery
}

\author{
Ranjith Kumar Kankala+, \\ Institute of Biomaterials and Tissue Engineering, Huaqiao University, Xiamen 361021, P. R. \\ China, Fujian Provincial Key Laboratory of Biochemical Technology, Huaqiao University, Xiamen \\ 361021, P. R. China \\ Jia Zhao ${ }^{+}$, \\ Institute of Biomaterials and Tissue Engineering, Huaqiao University, Xiamen 361021, P. R. China \\ Chen-Guang Liu, \\ Institute of Biomaterials and Tissue Engineering, Huaqiao University, Xiamen 361021, P. R. China \\ Xiao-Jie Song, \\ Institute of Biomaterials and Tissue Engineering, Huaqiao University, Xiamen 361021, P. R. China \\ Da-Yun Yang, \\ Fujian Key Laboratory for Translational Research in Cancer and Neurodegenerative Diseases, \\ Institute for Translational Medicine, School of Basic Medical Sciences, Fujian Medical University, \\ Fuzhou, Fujian 350108, P. R. China
}

Kai Zhu, Department of Cardiac Surgery, Zhongshan Hospital, Fudan University, Shanghai 200032, P. R. China

\section{Shi-Bin Wang,} Institute of Biomaterials and Tissue Engineering, Huaqiao University, Xiamen 361021, P. R. China, Fujian Provincial Key Laboratory of Biochemical Technology, Huaqiao University, Xiamen 361021, P. R. China

\section{Yu Shrike Zhang,}

Division of Engineering in Medicine, Brigham and Women's Hospital, Department of Medicine, Harvard Medical School, Cambridge, MA 02139, USA

\section{Ai-Zheng Chen} Institute of Biomaterials and Tissue Engineering, Huaqiao University, Xiamen 361021, P. R. China, Fujian Provincial Key Laboratory of Biochemical Technology, Huaqiao University, Xiamen 361021, P. R. China

\footnotetext{
azchen@hqu.edu.cn.

${ }^{[+]}$These authors contributed equally to this work

Supporting Information

Supporting Information is available from the Wiley Online Library or from the author.

Conflict of interest

The authors declare no conflict of interest.
} 


\section{Abstract}

Microscale cell carriers have recently garnered enormous interest in repairing tissue defects by avoiding substantial open surgeries using implants for tissue regeneration. In this study, we fabricated the highly open porous microspheres (HOPMs) using a microfluidic technique for harboring proliferating skeletal myoblasts and evaluating their feasibility towards cell delivery application in situ. These biocompatible HOPMs with particle sizes of 280-370 $\mu \mathrm{m}$ possessed open pores of 10-80 $\mu \mathrm{m}$ and interconnected paths. Such structure of the HOPMs conveniently provided a favorable microenvironment, where the cells were closely arranged in elongated shapes with the deposited extracellular matrix, facilitating cell adhesion and proliferation, as well as augmented myogenic differentiation. Furthermore, in vivo results in mice confirmed improved cell retention and vascularization, as well as partial myoblast differentiation. These modular cell-laden microcarriers potentially allow for in situ tissue construction after minimally invasive delivery providing a convenient means for regeneration medicine.

\section{Graphical Abstract}

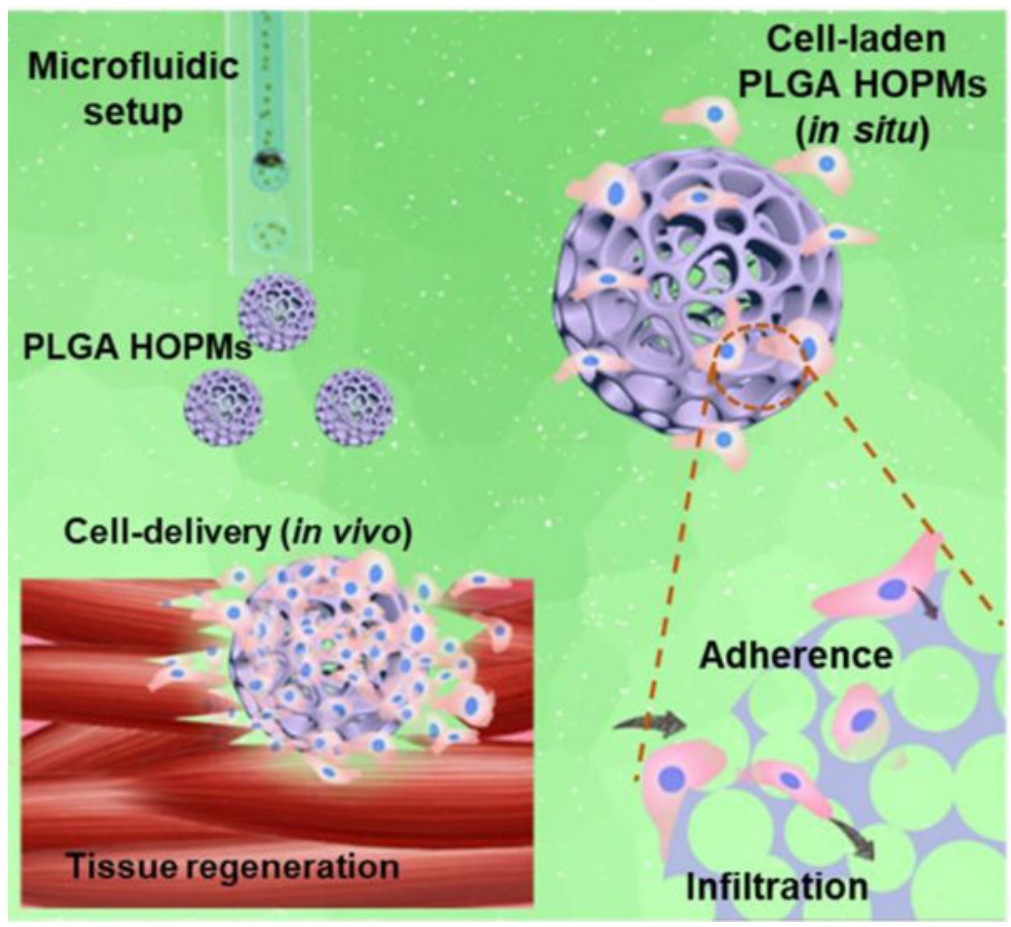

Highly open porous microspheres (HOPMs) are conveniently fabricated using a glass capillarybased microfluidic device setup and evaluated for their feasibility towards minimally invasive cell delivery-based tissue regeneration. These biocompatible HOPMs with interconnected paths expediently facilitated a high cell proliferation rate, and partial differentiation of skeletal myoblasts. These modular cell-laden microcarriers provide a convenient means for in situ repair of tissue defects and applications in regenerative medicine. 


\section{Keywords}

microfluidics; porous microspheres; cell carriers; minimally invasive delivery; tissue regeneration; Cell Delivery

\section{Introduction}

The field of tissue engineering aims to repair malfunctioned tissues by fabricating threedimensional (3D) biomimetic tissue constructs that mimic the microenvironment of their native counterparts, such as photocrosslinkable hydrogels, biodegradable porous scaffolds, and nano/microfibrous biocompatible materials, which provide efficient control over the microenvironments for tissue growth. ${ }^{[1]}$ Multiple studies have utilized biomaterials in an effort to fabricate artificial tissue constructs for repairing tissue damage and highlighting the significance of vascularization and innervation on tissue maturation. ${ }^{[2]}$ Nevertheless, the surgery sites in the strategies based on the implantation of tissue-engineered constructs are invasive and may generate severe inflammatory reactions resulting in the harsh adverse microenvironment, where the survival of cells remains low. ${ }^{[3]}$

In comparison, the injectable modularized units based on cell lamellae, cell-laden microgels, and cell-loaded microspheres obtained using various biofabrication approaches offer numerous advantages including ease of packing with cells, administered through a minimally invasive procedure at the site of application thus minimizing scar formation and allowing for improved cells retention compared to the direct injection of cells alone. ${ }^{[1 \mathrm{~d}, 4]}$ In this context, several biodegradable polymeric microspheres have been reported as cell carriers for tissue engineering applications. ${ }^{[5]}$ Notably, these cell-laden microspheres could further aggregate and result in the formation of microtissues. ${ }^{[6]}$ The utilization of porous architectures might be advantageous over non-porous carriers as the open and interconnected pores provide effective cell-carrying capacity and enable the supply of oxygen and nutrients for cell proliferation. ${ }^{[5 a, 7]}$ Even then, the applicability of currently reported porous microcarriers is still limited by their relatively small sizes of the pores and the interconnecting windows, leading to poor infiltration of cells into the bulk of the carriers. In our previous study, we have developed a type of poly(lactic-co-glycolic acid) (PLGA)-based porous microspheres with a uniform diameter of $c a .300 \mu \mathrm{m}$ and pore sizes of $c a .40 \mu \mathrm{m}$ for biomedical applications. ${ }^{[8]}$ The cells could grow throughout the entire volume of the microspheres at high viability, compared to that of the particles with small pores where only a few of the cells were present at the center, and cell death was prominent due to lack of oxygen and nutrients supply. ${ }^{[8 \mathrm{~b}, 9]}$ Therefore, it is required to produce highly open porous architectures with interconnected pathways for improved cell retention efficacy in situ, as well as effective delivery of cells and subsequent ability of cell growth in vivo.

Skeletal muscles possessing hierarchical architectures of integrated fascicular muscle fibers and the extracellular connective tissues, play a significant role in shape maintenance and voluntarily performed physical activities. ${ }^{[10]}$ More often, skeletal muscle damage due to exposure to myotoxic agents, extreme temperatures, and traumatic injuries leads to severe consequences including congenital disabilities, degenerative myopathy, and eventually 
paralysis. ${ }^{[11]}$ Due to the inadequate proliferation potential of multipotent stem cells in muscle that enable the spontaneous repair mechanism, different currently available treatment choices such as the traditional musculocutaneous flap transplantation and direct injection of cells, such as mesenchymal stem cells (MSCs), myoprogenitor cells, embryonic stem cells, or those derived from induced pluripotent stem cells (iPSCs), are often practiced for promoting muscle growth, maintenance, and repair. ${ }^{[2 c, 12]}$ However, the flap transplantation approach suffers from a significant limitation of donor site morbidity, leading to a longer restoration time for adequate nerve innervation and vascularization. ${ }^{[2 \mathrm{c}, 12 \mathrm{~b}, 12 \mathrm{c}]}$ To this end, the direct injection of cells leads to several shortcomings such as high mobility of injected cells from the desired site of action leading to poor retention. ${ }^{[3]}$ In addition, the expansion of culture for proportionally larger defect sizes is another challenging issue that remains to be addressed. ${ }^{[2 \mathrm{c}]}$ Moreover, the use of porous microcarriers for the delivery of skeletal myoblasts towards engineering muscle tissues is rarely reported.

Motivated by these facts, here we report the convenient generation of highly open porous microspheres (HOPMs) and evaluation towards their feasibility for cell delivery application (Figure 1). Initially, we fabricated PLGA microcarriers with particle sizes of 280-370 $\mu \mathrm{m}$ possessed open, heterogeneous pores of $10-80 \mu \mathrm{m}$, and interconnected paths using a glass capillary microfluidic device setup. ${ }^{[5 b, 13]}$ The physicochemical properties, degradability, and comprehensive biosafety evaluation of these HOPMs were investigated. Further, as a proof-of-concept, mouse skeletal myoblasts ( $\mathrm{C} 2 \mathrm{C} 12$ cells) were seeded into these biocompatible HOPMs, which resulted in the generation of individual modular cell-laden microcarriers in situ. The cytological behaviors of cells on microcarriers were analyzed by various techniques such as quantitative real-time polymerase chain reaction (qRT-PCR), immunofluorescence staining, and histology staining, to verify the fabrication of cell-laden individual porous globular microstructures in vitro. Finally, we investigated the feasibility of the myoblasts delivery from these HOPMs and the biocompatibility of these cell-laden microcarriers in vivo. We believe that our approach of cell delivery using HOPMs will be feasible to demonstrate the potential efficacy in repairing tissue defects and regenerative medicine.

\section{Results and Discussions}

\subsection{Optimization of fabrication parameters by Minitab}

In microfluidic processing of PLGA HOPMs, the uniform distribution of porogen (gelatin aqueous solution) in the emulsion droplets (PLGA solution in dichloromethane (DCM)) within the confined space and its subsequent removal lead to the formation of porous architectures. In this context, the Minitab full-factorial experimental design analysis (Table 1 and Figure S1) was employed to optimize different formulation parameters such as concentrations of porogen and PLGA as well as the W/O ratio (Table 2) as they play a crucial role in the control of particle as well as pore sizes of the microcarriers. The experimental results with respect to different combinations of such formulation parameters and their effects on the particle sizes and pore sizes of obtained PLGA HOPMs (Table 1) were consistent with the output of Minitab analysis. It is evident from Figure S1 that the change in the concentrations of PLGA as well as porogen (high and low levels of Minitab, 
Table 2), showed a significant effect, while the W/O ratio had no influence on the eventual particle size of HOPMs. However, all these formulation parameters had shown significant influences on the pore diameter of the PLGA HOPMs $(p<0.05)$. When the relative amount of gelatin in the same amount of PLGA was increased, the space occupied by gelatin in the unit volume increased noticeably leading to the growth of the average pore size and substantial reduction in the eventual particle size.

More often, the overall morphology and structure of the microparticles depend on the formation of emulsion droplets (dispersed phase) at the end of the glass capillary tube and subsequent W/O interfacial tension and the shear force of continuous phase acting on it. ${ }^{[5 b]}$ The morphological features revealed by scanning electron microscopy (SEM) observations (Figure 2) of the microcarriers prepared under different experimental conditions (optimized by Minitab design, Tables 1 and 2) were distinct due to the altered composition of emulsion droplets resulting in the difference in their viscosity values at varied formulation parameters. Particularly, the pore sizes of the microcarriers increased significantly with the increase of gelatin concentration (Table 2 and Figure 2), indicating that it was an essential factor during the fabrication of microcarriers. ${ }^{[8]}$ Furthermore, we believe that the pore sizes of PLGA HOPMs would play a crucial role over the particle sizes in terms of accommodating cells through augmented proliferation in bulk and their subsequent delivery in vivo. Moreover, the HOPMs at a high concentration of gelatin $(8.5 \%)$ had yielded microparticles with irregular shapes, as the concentration of porogen was relatively high to that of the PLGA solution. Still, gelatin is advantageous as a porogen over those based on gas-foaming such as ammonium bicarbonate in generating porous architectures, due to its enriched volatilization characteristics that provide enough time to form large pores. ${ }^{[14]}$ At the chosen formulation parameters (medium level of Table 2, run- 9 of Table 1), the spherically shaped microcarriers with an average particle size of $c a .320 \mu \mathrm{m}$ and highly open, heterogeneous porous architectures with interconnected cavities were produced (Figure 3A-C), which would facilitate sufficient space for the cells. Moreover, the changes in adjustable parameters of microfluidic processing such as needle gauge, emulsifying power, and flow rate of the dispersed phase had also shown significant influences on the particle size of the final microcarriers (Figure S2). It was observed from the results that an increase in needle gauge reduced the size of microparticles, which might be due to increased space limitation of emulsion droplet formation and the substantial shear force acting on the emulsion droplets. On the other hand, with the increase of emulsifying power and velocity ratio of dispersed and continuous phases, it was evident from the results that the average diameter of microparticles had shown mixed trends, i.e., decrease initially and increase further with the elevated value of a respective parameter. However, the microcarriers in all the groups resulted in open structures with numerous large and interconnected pores. Considering the pore size of microcarriers as an important factor for cell delivery application, the formulation as well as processing parameters for the generation of HOPMs included, PLGA concentration of $2 \%, \mathrm{~W} / \mathrm{O}$ ratio of $1: 2.4$, gelatin concentration of $7.5 \%$, needle gauge of 26 $\mathrm{G}$, emulsifying power of $200 \mathrm{~W}$, and flow ratio of the dispersion phase to the continuous phase of 2:0.05, were selected as the optimal conditions for further experiments. 


\subsection{Physical characterizations}

Based on the optimization results of Minitab analysis (Table 1 and Figure 2), the carrier size was further calculated by analysis of 200 randomly selected particles, which represented an average diameter of $320 \mu \mathrm{m}$ (Figure 3D) and pore diameters ranging from 10 to $80 \mu \mathrm{m}$ (Figure 3E). Moreover, the cross-sectional image also suggested that the interiors of the PLGA HOPMs possessed highly porous architecture with interconnected cavities (Figure 3C). The globular microcarriers with appropriate particle size and large pore size distribution along with interconnected cavities have been shown to be more conducive to adhesion, spreading, and growth of cells. ${ }^{[7 \mathrm{a}]}$ Huang and coworkers demonstrated the effect of micropore diameter on the proliferation of human amniotic fluid-derived stem cells (hAFSCs), indicating that the average pore size of $40 \mu \mathrm{m}$ facilitated sufficient penetration of cells into the bulk of microcarriers and the appropriate size of such microcarriers similar to that of our HOPMs was convenient for injection. ${ }^{[15]}$

Furthermore, the PLGA HOPMs were systematically characterized in comparison with the raw PLGA material, to provide an experimental basis for further investigations that include biocompatibility evaluation and construction of the modular cell-laden microcarriers in situ. As anticipated, Fourier-transform infrared (FTIR) spectra exploring the chemical functionalities of the PLGA HOPMs (Figure S3A) indicated no structural changes in PLGA during the microfluidic processing. The sharp peak at $1763 \mathrm{~cm}^{-1}$ could be ascribed to $-\mathrm{C}=\mathrm{O}$ stretch vibration of carboxylate groups. In addition, the absorption peaks of 1635 and 1460 $\mathrm{cm}^{-1}$ could be attributed to the amide I and amide II vibrations, respectively, and a sharp peak at ca. $2982 \mathrm{~cm}^{-1}$ could be ascribed to-C-H stretch. ${ }^{[16]}$ Moreover, the X-ray diffraction (XRD) patterns also exhibited that there existed a halo-shaped broad characteristic diffraction peak $\left(10-30^{\circ}\right)$ in the PLGA HOPMs similar to that of the raw PLGA material (Figure S3B), revealing that both the materials were in the amorphous state. Indeed, it is generally considered that the rough surface of the microcarriers often favors and significantly augments the adhesion of cells to carriers. ${ }^{[1 \mathrm{~d}, 1 \mathrm{f}, 17]}$ However, it should also be noted that, although there exists no direct correlation with the existing state of the material for cell delivery application, the amorphous state of a material significantly enables the increase in its surface wettability over crystalline materials, possibly facilitating cell adhesion along with the improved hydrophilicity of PLGA. ${ }^{[17]}$ Comparatively, the intensity of a peak in the PLGA HOPMs sample was reduced, which might be due to the plasticizing effect of DCM on PLGA. Furthermore, various thermal analyses of the PLGA HOPMs were recorded to explore the effect of surface porosity of the designed microcarriers on the thermal properties of the material. The differential scanning calorimetry (DSC, Figure S3C) analysis of PLGA HOPMs revealed a slight difference in the glass transition temperature $\left(\mathrm{T}_{\mathrm{g}}\right)$ of the PLGA HOPMs $\left(52.9^{\circ} \mathrm{C}\right)$ compared to that of the raw PLGA $\left(53.4^{\circ} \mathrm{C}\right)$ due to larger surface area of the final construct leading to significant heat transfer. ${ }^{[7 \mathrm{j}]}$ Accordingly, the change in $\mathrm{T}_{\mathrm{g}}$ demonstrated that the fabricated HOPMs possessed significant surface porosity without any signs of disintegration. Moreover, the slight difference in $T_{g}$ of PLGA might be due to the enhancement of mobility of the PLGA molecular chains during microfluidic processing. ${ }^{[7 \mathrm{j}]}$ However, the slight change in $\mathrm{T}_{\mathrm{g}}$ was anticipated to have no significant influence on the performance of HOPMs during cell delivery. Furthermore, the thermogravimetric analysis (TGA) curves represented that the stability of the processed 
PLGA was slightly higher and retained its structural integrity until $300{ }^{\circ} \mathrm{C}$ compared to that of the raw PLGA, which started degrading at ca. $250^{\circ} \mathrm{C}$ (Figure S3D and E). Although the $\mathrm{T}_{\mathrm{g}}$ of PLGA HOPMs was slightly reduced, the stability was anticipated to improve due to the orderly arrangement of PLGA molecules during the solidification. These results explicitly clarified that the PLGA was robust during the fabrication of HOPMs without major structural changes.

Prior to the application of PLGA HOPMs for myoblast delivery in situ, the headspace gas chromatography technique was further used to detect the residual amount of organic solvent, DCM, which would significantly affect the adhesion and proliferation of cells in the porous globular microstructures. As shown in Figure 3F, the solvent absorption peak at a retention time $\left(t_{R}\right)$ of 5.4 min corresponding to DCM (Figure 3F-i) was significantly lower (less than $1 \mathrm{ppm}$ ) in the PLGA HOPMs (Figure 3F-ii), demonstrating that DCM was effectively extracted during the preparation of microcarriers. Such structures would potentially provide high compatibility without exerting any influence on cell activities, indicating their safety as microcarriers for cell delivery.

Further, we investigated the degradability in vitro of PLGA HOPMs by exposing them in the phosphate-buffered saline (PBS, pH-7.4) for 7 weeks. It was observed from the results that the microcarriers showed the miniature apertures on the surface walls as well as the distorted interconnecting windows in the $2^{\text {nd }}$ week and the signs of degradation were augmented over the incubation time, attributing to their highly porous 3D architectures (Figure 4A).

However, the overall particle diameter of the microcarriers remained largely unchanged (Figure 4A, inset). Moreover, it was also evident that the resultant $\mathrm{pH}$ value of the buffer (Figure 4B) and the residual mass of the PLGA HOPMs (Figure 4C) were substantially reduced with the incubation time. These results were in agreement with the data reported from Lin and coworkers, where the PLGA microspheres unveiled potential degradation behavior both in vitro as well as in vivo. ${ }^{[18]}$

To demonstrate the injectability of the designed globular microcarriers in vitro, we investigated the expedient flow of microcarriers through various gauges (14-22G) of syringe needles. It was evident from the results that the needles with inner diameters higher than 0.9 $\mathrm{mm}(20 \mathrm{G})$ were convenient for the flow of the microcarriers at success rates greater than $90 \%$, while the rates were slightly reduced in the case of needles with inner diameters of lesser than $0.9 \mathrm{~mm}$ (Table S2). However, the passage efficiencies were greater than $75 \%$ in all the chosen gauges of syringe needles. Furthermore, the SEM images of PLGA HOPMs confirmed that the morphology of the microcarriers remained unchanged in the case of needles larger than 20G, while the smaller needles had resulted in a slight change of the microcarrier shape to ellipsoid (Figure S4), possibly due to mechanical abrasion during injections. These results revealed that the injectability of PLGA HOPMs through these tested range of needle sizes was expedient and could potentially be well-suited to explore them for minimally invasive cell delivery application in vivo.

\subsection{Biocompatibility}

Despite the compatibility as well as sufficient degradability of PLGA for biomedical applications, the use of porogens as well as subjecting the polymer to multistep processing 
may alter its structure leading to cytocompatibility issues, which demand the comprehensive biosafety evaluation of PLGA HOPMs. ${ }^{[19]}$ Herein, we evaluated the biocompatibility of these designed microcarriers ranging from the cellular to the animal levels by investigating the cytotoxic events using cell cultures in vitro, hemocompatibility assays ex vivo, and acute toxicity studies in vivo in nude mice.

Initially, the relative proliferation of $\mathrm{C} 2 \mathrm{C} 12$ cells on PLGA HOPMs showed that the viability of cells was higher than $75 \%$ in all the treatments at different exposure times relative to the negative control treatment group (medium alone), while the viability dropped lower to $10 \%$ in the positive control treatment group ( $0.64 \%$ of phenol in medium) (Figure $5 \mathrm{~A}-\mathrm{i}$ ), indicating the cytocompatibility of the microcarriers. Furthermore, the optical micrographs of cells treated with the PLGA HOPMs displayed normal fibrous morphologies with favorable cell adherence and growth (Figure 5Aiv-vi) similar to that of the negative control (Figure 5A-ii), revealing no significant changes in the morphology of myoblasts in the presence of PLGA HOPMs. Contrarily, the positive control treatment resulted in the typical apoptotic morphology of cells with rounded shape (Figure 5A-iii). These results were in agreement with the other reports, where the PLGA-based carriers were shown to exhibit low cytotoxicity on different cell types such as Calu-3 cells and A549 cells. ${ }^{[20]}$

Furthermore, the hemocompatibility investigation of PLGA HOPMs using rabbit blood revealed that the hemolysis rates of the microcarriers at different concentrations were no more than 3\%, indicating their excellent compatibility with blood (Figure 5B). In addition, the acute toxicity study was performed by administering the PLGA HOPMs (doses: 30, 150, and $300 \mathrm{mg} / \mathrm{kg}$ ) through intraperitoneal injection in Kunming (KM) mice ( $\mathrm{n}=10)$ (Figure 5C). It showed no significant changes in the body weight of animals treated with HOPMs during the 72-h observation period, similar to the negative control (normal saline) group, in which the animals were able to exercise freely, with normal appetite and good growth without any adverse symptoms (Table S3). Contrarily, the positive control treatment group (6.4\% phenol) showed obvious toxic signs and the animals were dead after intraperitoneal injection. In addition, the morphological assessment of major organs, as well as the pathological examination by hematoxylin and eosin (H\&E) staining of the liver were performed in randomly selected mice from each group. From Figure 5D, it was evident that no noticeable signs of inflammation, denaturation, necrosis, and other symptoms in the organs of mice in the experimental groups were observed. Moreover, the pathophysiological features of the liver explants showed no major changes in the structures, and no inflammation and interlobular necrosis were observed, in the experimental group in comparison to the negative control group (Figure 5D). Whereas, the hepatocytes in the positive control treatment group seemed to become loosely arranged, showing signs of small focal cells in the hepatic lobule, infiltration of a small number of inflammatory cells in the interstitium, hepatic edema, moderate degeneration, and resulting necrosis (Figure 5D), which were in agreement with the reported data from the literature. ${ }^{[21]}$

\subsection{Construction and characterization of cell-laden HOPMs}

Prior to the fabrication of cell-laden HOPMs for cell delivery-based regeneration, we investigated the adsorption of proteins on the microcarriers by exposing them to serum 
proteins to evaluate the cell adhesion ability of this type of biomimetic substitute. ${ }^{[19 c, 22]}$ As shown in Figure S5, it was evident that the kinetics of adsorption, as well as desorption of proteins on the PLGA HOPMs, had achieved dynamic equilibrium in $3 \mathrm{~h}$, demonstrating that the cells could well-attach to the surface of HOPMs and promote improved cell retention efficacy in situ.

As a proof-of-concept, here we used C2C12 cells for the construction of cell-laden HOPMs for minimally invasive skeletal myoblast delivery. The effects of the culture conditions (static as well as dynamic) on the adhesion and the growth of myoblasts on PLGA HOPMs were investigated in vitro. The dynamic culture was performed by incubating the microcarriers in the cell suspension with a continuous supply of nutrients and oxygen, while the static culture was maintained in the fixed media volume. Confocal laser scanning microscopy (CLSM) images in Figure 6A-i depict that the number of $\mathrm{C} 2 \mathrm{C} 12$ cells (stained for nuclei) gradually increased on the PLGA HOPMs from 3 to $48 \mathrm{~h}$ post-inoculation in both cases. Compared with the static culture, the cell distribution in the dynamic culture was more uniform and the cell density was higher due to a continuous supply of nutrients and oxygen leading to faster proliferation. ${ }^{[23]}$ In addition, it was observed that the adhesion rate of myoblasts was also higher in the dynamic culture compared to that of the static culture (Figure 6A-ii). To further characterize the growth and proliferation of $\mathrm{C} 2 \mathrm{C} 12$ cells adhered to PLGA HOPMs, we recorded the cell number on the microcarriers with respect to culture time. Figure 6A-iii depicts that the $\mathrm{C} 2 \mathrm{C} 12$ cells had consistent growth and proliferation on microcarriers with monotonically increasing trends. The cell growth was slightly higher initially in the static culture method compared to that of the dynamic culture. However, the growth trend increased rapidly from the $4^{\text {th }}$ day in the dynamic culture and had shown a favorable growth in 15 days. Together, the dynamic culture method was advantageous in cultivating cells at high density, which effectively promoted cell growth and possibly the generation of ECM. ${ }^{[24]}$ To this end, it was evident from the results that the highly porous architectures of HOPMs would provide efficient mass transfer and ample space facilitating myoblast growth, migration, and distribution throughout the microcarriers.

Furthermore, the acridine orange/ethidium bromide (AO/EB) co-staining of cell-laden HOPMs has drawn similar conclusions relevant to the growth and adherence of myoblasts in the HOPMs (Figure 6B). The AO-labeled cells with green fluorescence gradually increased in number with the prolongation of culture time, while the dead cells labeled by EB (red fluorescence) were hardly observed, demonstrating that the cells distributed in the PLGA HOPMs successfully proliferated and no signs of negative events were observed. It has been previously demonstrated by Wei and coworkers that, despite the structural similarity concerning the particle size as well as porous architectures, poly(lactic acid) (PLA)-based microspheres often end up with a slight reduction in the viability of cells in the porous structures after 1 week, which may be attributed to the acidic environment due to degradation of PLA microparticles releasing lactic acid. ${ }^{[7 e]}$ With regard to this, we believe that the lactic acid amount was comparatively low in the case of PLGA-based HOPMs. The PLGA HOPMs also remained stable during the entire culture period, indicating that they could be well-suited to provide structural support for myoblast growth proliferation in vitro. 
To further evaluate the functions of the formed skeletal myoblast-laden HOPMs at the molecular level, the immunohistochemical staining, as well as histological analysis and gene expression profiles of myoblasts on HOPMs were investigated. The myogenesis-specific biomarkers (desmin and myosin heavy chain (MYH) 1) exhibited strong fluorescence (Figure 6C), indicating that the high density of the myoblasts in the HOPMs might have facilitated their augmented myogenic differentiation. The result of H\&E staining of the transverse cross-section of the cell-laden PLGA HOPMs is shown in Figure 6D, in which the myoblasts were evenly distributed in the microcarrier occupying the entire space along with the secreted ECM. The cells in the PLGA HOPMs were elongated, resulting in the partially aligned differentiated myotubes. From Figure 6E, the qRT-PCR results revealed that the expressions of the myogenesis-specific transcription factors, myogenic differentiation 1 (MyoD1), myogenic factor 5 (Myf 5), and paired box 7 (Pax7) were relatively high, representing the signs of myogenic differentiation of cells in the PLGA HOPMs. Together, these results ranging from the determination of cell proliferation to the myogenic protein/ gene expressions confirmed that the skeletal myoblasts-laden HOPMs were successfully constructed at good retention efficacy and proliferation of cells along with partial differentiation in vitro. These consequences happened to be favorable due to highly porous architectures that facilitated sufficient space for infiltration of cells and exchange of nutrients as well as providing a biocompatible microenvironment for cell retention efficacy in the bulk. Consequently, we anticipate that they could be feasible as minimally invasive cell delivery vehicles effectively for tissue repair.

\subsection{Biological performance of cell-laden HOPMs in vivo}

Further, the myoblast growth and differentiation accounting for successful delivery of cells from the microcarriers along with the compatibility attribute of designed cell-laden PLGA HOPMs in vivo were investigated by injecting them subcutaneously in healthy nude mice. The explants of muscle tissues showed that they were successfully formed by the locally delivered cell-laden PLGA HOPMs, and yielded significantly larger tissue sizes compared to those of other treatment groups (Figure 7A), attributing to their highly porous 3D architectures and excellent cell retention efficacy. It was evident from the staining results (H\&E and Masson's trichrome) that the injected cell suspension as well as cell-laden PLGA HOPMs resulted in the formation of tissues with orderly arrangement and dense fiber-like structures (Figure 7B/C-i and ii, respectively), while the control (saline), as well as blank (carrier alone) treatment groups, did not alter the structures of the native muscle fascicle (Figure S6A/B-i and ii, respectively). Moreover, it should be noted that the PLGA HOPMs completely degraded within the 6-week period, possibly due to its highly porous structure leading to fast degradation and tissue integration. The TUNEL staining results showed minor signs of apoptosis in the case of mice injected with the individual cells and cell-laden HOPMs (Figure 7D-i and ii, respectively) compared to the control treatment group, where no apoptotic cells were observed (Figure S6C). The reason behind the slight apoptosis of cells might be the acidic environment generated by minor amounts of lactic acid from degraded PLGA at the site of injection, which, however, would require further in-depth studies in the future. However, the cells were slightly apoptotic in the case of cell-laden HOPMs compared to the isolated cells treated group. Although the staining results of cellladen HOPMs treatment seemed to have not led to the formation of fully differentiated 
myofibers present in the native skeletal muscle, they facilitated the growth of new tissues with notably larger dimensions than that in the cell-alone group due to augmented proliferation of delivered myoblasts in situ as well as in the microenvironment in vivo. In addition, these attributes demonstrated that the minimally invasive cell-laden HOPMs were highly compatible and might enable their utilization as delivery vehicles in the future.

During tissue regeneration, vascularization plays a key role in their growth as it maintains hemostasis by supplying the required nutrients as well as oxygen and removal of metabolic waste. ${ }^{[1 \mathrm{~b}, 1 \mathrm{~d}, 1 \mathrm{e}]}$ We speculated that the slightly higher apoptosis in the delivered cell-laden PLGA HOPMs could also associate with their differential vascularization pattern due to the increased need for blood vessels. Indeed, analyses of vascular-specific genes (angiotensinconverting enzyme 2 (ACE 2), angiotensin, and vascular endothelial growth factor A (VEGF-A)) by PCR and their respective proteins by Western blot analysis revealed that the cell-laden HOPMs treatment group exhibited higher expressions of these markers, in comparison to that of other treatment groups (control, individual cells, and microcarriers alone, Figure 7E, F). Histology data also echoed the molecular assays, where ingrowth of microvessels was observed in the newly formed muscular tissues in the cell-laden HOPMs treatment group (arrows in Figure 7B, C-ii) but not the group with the delivery of individual cells (Figure 7B, C-i). Although it was difficult in differentiating the delivered cells and host cells from the staining results, the proliferation of myoblasts in situ as well as in the microenvironment in vivo and the high expression of the various myoblast and vascular markers would represent that the cells with high retention efficacy in the porous architectures of HOPMs were successfully delivered, and ingrowth of microvessels was also observed in the newly formed muscular tissues. These results of successful encapsulation of cells and their delivery in vivo, as well as biocompatibility, were anticipated to demonstrate the feasibility of utilizing these designed cell-laden HOPMs for tissue repair and regenerative medicine.

The vascularization and differentiation of myoblasts, as well as their maturation, were additionally confirmed by immunohistochemical staining of myogenic markers, desmin, MYH1, smooth muscle actin (SMA), and CD31. It was evident from the results that more myoblasts with high expressions of these specific proteins were found in the injected cellladen HOPMs group, and low expressions in the group treated with HOPMs alone (Figure 8). The local delivery of cells through injection of cell-laden PLGA HOPMs effectively facilitated the growth and differentiation of myoblasts concomitantly with neoangiogenesis, which could be attributed to highly porous architectures as well as biocompatibility of the PLGA HOPMs. Together, it can be concluded that the minimally invasive delivery of cells from the porous microcarriers could be beneficial for repairing the tissue defects and enable subsequent muscle regeneration.

\section{Conclusions}

In summary, we successfully fabricated PLGA HOPMs as injectable 3D porous microspheres by microfluidic technology for minimally invasive tissue regeneration. These biocompatible HOPMs with interconnected paths expediently facilitated a high rate of cell adhesion, continuous proliferation, and augmented myogenic differentiation of $\mathrm{C} 2 \mathrm{C} 12$ 
skeletal myoblasts that were closely arranged in fibrous shapes with established ECM. Furthermore, these modular cell-laden HOPMs exhibited a strong potential for myoblast differentiation in mice facilitating the growth of skeletal myoblasts concomitantly with vascularization. Hence, these modular cell-laden HOPMs could be feasibly constructed in situ after minimally invasive delivery using a percutaneous needle and provide a convenient means for myoblast differentiation and skeletal muscle regeneration. It should be noted that, while the $\mathrm{C} 2 \mathrm{C} 12$ cells as a model for proof-of-concept in this work did not completely mature to myofibers in vivo, we believe that the utilization of stem cells combined with predelivery in vitro differentiation in these designed modular architectures can eventually result in efficient skeletal muscle regeneration.

\section{Experimental section}

\subsection{Materials}

All the reagents, chemicals, and organic solvents were of the analytical grade at the highest purity, commercially available and were used without further purification. All the chemicals were obtained from Sigma-Aldrich (St. Louis, USA) unless otherwise noted.

\subsection{Fabrication of HOPMs}

PLGA (lactide: glycolide 75:25, 66-107 kDa) HOPMs were prepared by using the microfluidic technology. ${ }^{[8 \mathrm{a}]}$ For achieving uniform-sized microparticles, a customized microfluidic setup composed of a polyvinyl chloride (PVC) tube, a glass capillary, and a needle was used. First, the W/O emulsion was prepared by dissolving PLGA in DCM as the oil phase and then the aqueous solution of gelatin was added as the internal water phase. The initial emulsion was stabilized by ultrasonic emulsification (ultrasonic treatment for $1 \mathrm{~s}$, interval $2 \mathrm{~s}$ ). Second, the initial emulsion was introduced into the microfluidic device as the discontinuous phase, and the $\mathrm{W}_{1} / \mathrm{O} / \mathrm{W}_{2}$ emulsion was formed under the dispersion of continuous polyvinyl alcohol (PVA) solution. The glass capillary was inserted into an ice water bath, and the PLGA microspheres were collected. Gelatin was then removed from the PLGA microspheres by exposing the mixture to deionized water at $40{ }^{\circ} \mathrm{C}$ for $1 \mathrm{~h}$ and then the microspheres were washed several times with deionized water to remove the traces of gelatin. Finally, the PLGA HOPMs were obtained after freeze-drying for $24 \mathrm{~h}$.

\subsection{Optimization of processing parameters}

To explore the effect of processing parameters such as polymer concentration, W/O ratio, and gelatin concentration on the morphology (shape, particle size, and pore size) of the microcarriers, herein we used a full-factorial experimental design based on the Minitab software following the reported procedure. ${ }^{[15]}$ The factors and levels of Minitab fullfactorial design are shown in Table 2.

\subsection{Physical characterizations}

The surface morphology of microparticles was investigated by field-emission SEM (FESEM, S-4800, HITACHI, Tokyo, Japan). Samples were prepared by dispersing PLGA HOPMs deposited on conductive adhesive dried under room temperature and sputter-coated with gold. Nano Measurer 1.2 software (Shanghai, China) was used to determine the average 
diameter of the randomly selected microparticles $(n=200)$. FTIR (Nicolet iS50,

ThermoFisher, Waltham, USA) spectra were recorded in the wavenumber range of 4000 $400 \mathrm{~cm}^{-1}$ using potassium bromide (KBr, Fisher Scientific Ltd., Loughborough, UK) pellet method. Samples were prepared by mixing approximately $2 \mathrm{mg}$ of finely ground HOPMs after subjecting the microparticles to freeze-drying overnight, with dried $\mathrm{KBr}$ at a 1:200 ratio, pressed into a thin film, and further subjected to analysis. The structures of the HOPMs were analyzed by XRD with a Scintag X1 diffractometer (Scintag Inc., Sunnyvale, USA) using copper $\mathrm{K}_{\mathrm{a}}$ radiation $(60 \mathrm{kV}, 60 \mathrm{~mA})$ at a scanning speed of $1.0^{\circ} / \mathrm{min}$. Weight loss events were recorded using TGA thermal analyzer (TGA Q50 V20, 13 Build 39) and DSC thermal analysis (both from Universal V4.5A TA Instruments, New Castle, USA) following the set of test parameters of the instrument (for TG-DTA: temperature range $=20$ to $500{ }^{\circ} \mathrm{C}$, heating rate $=10^{\circ} \mathrm{C} / \mathrm{min}$, gas flow $=20 \mathrm{~mL} / \mathrm{min}$; for DSC: temperature range $=$ 20 to $100{ }^{\circ} \mathrm{C}$, temperature rising rate $=10{ }^{\circ} \mathrm{C} / \mathrm{min}$, gas flow $=20 \mathrm{~mL} / \mathrm{min}$ ) in argon atmosphere. Organic solvent residual amounts in the microparticles were determined by headspace gas chromatography (GC, Agilent, Santa Clara, USA) using DB-624 capillary column, and the chromatographic conditions were set as column temperature range $=35$ to $230{ }^{\circ} \mathrm{C}$, and heating rate $=20^{\circ} \mathrm{C}$; detector (FID) temperature $=250{ }^{\circ} \mathrm{C}$; carrier gas: nitrogen (flow rate: $0.9 \mathrm{~mL} / \mathrm{min}$ ); and distributary mode: flow ratio $=20: 1$.

4.4.1. Degradation analysis-The microcarriers were subjected to degradation analysis by maintaining the conditions mimicking the physiological environments concerning the $\mathrm{pH}$ and temperature of the dispersion buffer. The designed PLGA HOPMs (approximately $20 \mathrm{mg}$ ) were exposed to PBS (pH-7.4, $10 \mathrm{~mL}$ ) and placed in the rotary incubator $\left(37^{\circ} \mathrm{C}, 200 \mathrm{rpm}\right)$. The investigation was continued by monitoring the $\mathrm{pH}$ value of the dispersion buffer and concomitantly replenishing the equal amount of PBS every week. The microcarriers were washed with PBS and freeze-dried overnight and subjected to various analyses, including SEM observations as well as the residual weight measurements. The experiments were repeated in triplicates.

4.4.2. Injectability-To demonstrate the in vitro injectability of the designed microspheres, we investigated the convenient passage of microspheres through various gauges $(14-22 G)$ of the syringe needles. Briefly, microspheres $(n=50)$ were immersed in ultrapure water $(30 \mathrm{~mL})$ and then injected slowly after filling them in a 50-mL syringe. Further, the passage efficiency was recorded by enumerating the number of delivered microspheres from the needle. The experiments were repeated in triplicates.

\subsection{Biocompatibility investigations}

4.5.1. Cell culture-The skeletal myoblasts from mouse (C2C12, purchased from American Type Culture Collection, ATCC, Manassas, USA) cultured in Dulbecco's modified Eagle medium (DMEM, Gibco, Grand Island, USA) were used throughout to study the biocompatibility as well as microtissue formation. DMEM was supplemented with $10 \%$ (v/v) fetal bovine serum (FBS, Gibco) and penicillin-streptomycin (100 U/mL, Gibco). Cells were incubated in a humidified incubator maintained at $37{ }^{\circ} \mathrm{C}$ in $5 \% \mathrm{CO}_{2}$. 
4.5.2. In vitro cytotoxicity-The CCK-8 assay was used to measure the cytotoxicity in vitro of the prepared PLGA HOPMs. C2C12 cells were seeded at a density of $1 \times 10^{4}$ cells per well of a 96-well plate. After $24 \mathrm{~h}$ of incubation, the media were removed from the wells, and the cells were washed twice with PBS. Then, $100 \mu \mathrm{L}$ of media containing suspensions of the microspheres at various concentrations $(0.25,0.50$, and $1 \mathrm{mg} / \mathrm{mL})$ were added to cells along with negative control/blank treatments. In addition, phenol was added to a group of cells considered as the positive control group. After $4 \mathrm{~h}$ of incubation, $10 \mu \mathrm{L}$ of the CCK-8 working solution was added to each well and incubated for pre-determined time intervals $(24,48$, and $72 \mathrm{~h})$. The optical density (OD) was detected using a microplate reader (SpectraMaxM5, Molecular Devices, San Jose, USA) at the wavelength of $450 \mathrm{~nm}$, and the relative proliferation rate (RGR) was calculated as indicated below.

$$
\begin{aligned}
& R G R \%=\left(\text { sample group } O D_{450}-\text { blank group } O D_{450}\right) \\
& /\left(\text { positive control group } O D_{450^{-}} \text {blank group } O D_{450}\right) \times 100
\end{aligned}
$$

4.5.3. Ethical considerations-All experimental protocols utilizing animals were reviewed and performed according to the Experimental Animal Ethics Committee of Fujian Medical University following the guidelines of the National Institute of Health Animal Care and the Animal Management Rules of the Ministry of Health of the People's Republic of China. The animals were given utmost human care during the courses of the experiments.

4.5.4. Ex vivo hemolysis-Initially, the fresh blood $(2 \mathrm{~mL})$ was collected from the rabbit ear vein using heparin sodium, and $2.5 \mathrm{ml}$ of saline was added to dilute the blood. An ample amount of diluted blood $(0.2 \mathrm{~mL})$ was added to tubes containing various samples including normal saline (negative control group), the microspheres $(0.25,0.50$, and $1 \mathrm{mg}$ / $\mathrm{mL}$ ), and deionized water (positive control group), and the samples were incubated for 30 $\mathrm{min}$. The samples were then centrifuged for $5 \mathrm{~min}$ at $2500 \mathrm{rpm}$, and it was ensured that the supernatants were clear with no debris. The OD values of the supernatants were then measured by UV-vis spectrophotometer (Genequant-1300, GE Healthcare Biosciences, Boston, USA) at $545 \mathrm{~nm}$. The experiments were repeated in triplicates. The hemolysis rate of the microcarriers was calculated using the following formula.

$$
\begin{aligned}
& \text { Hemolysis rate }(\%)=\left(\text { sample group } O D_{545}-\text { negative control } O D_{545}\right) / \\
& \left(\text { positive control } O D_{545}-\text { negative control } O D_{545}\right) \times 100
\end{aligned}
$$

4.5.5. Acute systemic toxicity-The systemic toxicity evaluations were performed on KM mice (weighing 20-30 g) as an animal model (Wu Animal Center, Xiamen, China). During the course of the experiment, the animals were randomly divided into various groups $(\mathrm{n}=10)$ of negative control (normal saline), microparticle treatment $(1,5,10 \mathrm{mg} / \mathrm{mL}$ of microparticle suspension), and positive control (6.4\% phenol) groups, and the doses were injected through the intraperitoneal route into the mice. After completion of the intraperitoneal injections, we observed and recorded the appetite, activity state, and toxic 
symptoms of the mice. Simultaneously, the weights of the mice were also recorded regularly at each time point. In addition, the morphologies of major organs were observed by randomly selecting an animal in each experimental group. Furthermore, the dissected liver sections were stained with $\mathrm{H} \& \mathrm{E}$ for observing the pathological changes through microscopic examinations.

\subsection{Construction and characterizations of cell-laden HOPMs}

Prior to construction of the cell-laden HOPMs, the protein adsorption kinetics of the microcarriers was determined using the standard Bradford assay kit (Bio-Rad, Hercules, USA). Further, the growth of cells in the microparticles was investigated under static as well as dynamic cultures. In static culture, the logarithmic growth of $\mathrm{C} 2 \mathrm{C} 12$ cells was taken into account to adjust the cell concentration to $1.6 \times 10^{4}$ cells $/ \mathrm{mL}$, and $200 \mu \mathrm{L}$ of cell suspension was placed along with the microcarriers in each well of a 96-well plate. After 3, 9, 24, and $48 \mathrm{~h}$ of incubation, the microcarriers were washed once with PBS to remove the nonadherent cells. The cells were then fixed with $4 \%$ paraformaldehyde for $30 \mathrm{~min}$, stained with DAPI for $10 \mathrm{~min}$, and observed under the CLSM (Carl Zeiss Meta LSM510, Wetzlar, Germany). With respect to the dynamic culture, the cell concentration was chosen as $8 \times 10^{5}$ cells $/ \mathrm{mL}$.

Furthermore, the cell count, as well as adhesion rate on the microparticles, were measured at respective time intervals by dissociating the cells using trypsin-ethylenediamine tetraacetic acid (EDTA) solution for $30 \mathrm{~min}$. Cell number was then estimated by using the conventional Neubauer Chamber Cell Counting procedure, and the cell adhesion rate was calculated using the following formula.

Cell adhesion rate $(\%)=$ cell adhesion /cell inoculation volume $\times 100$

Cell proliferation on the microcarriers in both static and dynamic cultures was determined by using the CCK-8 assay (see Section 4.5.2.) after incubation for 1, 2, 4, 7, 11, and 15 days. In addition, the cell viability over the microparticles (incubated for 3, 5, and 12 days) was visualized by subjecting the treatments to CLSM imaging after being stained by the AO/EB working solution (Aladdin Industrial Inc., Shanghai, China).

\subsection{Gene expression profiles of myoblasts on PLGA HOPMs}

The regulation of myoblast-specific gene expressions was measured with the qRT-PCR technique. Initially, the total RNA was extracted from the myoblasts (after culturing for 20 days on the HOPMs) and were reverse-transcribed into complementary DNA (cDNA). Expressions of genes induced by myogenic induction were measured by the StepOnePlus real-time PCR system (Applied Biosystems, Foster City, USA; reaction details are provided in Table S4) with the M-MuLV first chain cDNA synthesis kit (Shanghai Bioengineering Ltd., Shanghai, China). Each cycle consisted of the following temperatures and times: $94^{\circ} \mathrm{C}$ for $3 \mathrm{~s}$ and $60^{\circ} \mathrm{C}$ for $30 \mathrm{~s} \cdot{ }^{[4 \mathrm{i}]}$ The sequences of primers are summarized in Table 3. 


\subsection{Histological examination of cells-laden PLGA HOPMs}

4.8.1. H\&E staining-To observe the histological characteristics of myoblast-laden PLGA HOPMs, we performed H\&E staining of the cells. First, the cells in the HOPMs were fixed using $4 \%$ paraformaldehyde for $24 \mathrm{~h}$, following which they were embedded in paraffin and sliced 4-5 $\mu \mathrm{m}$ in thickness. Subsequently, they were dewaxed and rehydrated by soaking the slices in xylene for $5 \mathrm{~min}$, washed once with anhydrous ethanol for $5 \mathrm{~min}$, and then thrice with PBS. Finally, the H\&E staining was performed, and then gum-sealed for CLSM imaging.

4.8.2. Immunofluorescence staining-The immunofluorescence staining was also performed. The cell-laden HOPMs were first fixed with $4 \%$ of polyoxymethylene for $1 \mathrm{~h}$, followed by $0.5 \%$ Triton-X 100 treatment for $30 \mathrm{~min}$; then anti-homologous serum treatment was conducted for $60 \mathrm{~min}$, and the cell-laden HOPMs were incubated at $4{ }^{\circ} \mathrm{C}$ for overnight. After a PBS wash and immersion in PBS for $1 \mathrm{~h}$, the samples were added with DAPI for 10 min for nuclei counterstaining, and finally, the fluorescence images were captured by CLSM.

\subsection{In vivo investigations}

Balb/c nude mice (weighing 20-30 g, 6-week old) were used as a model to demonstrate the minimally invasive delivery of cells and their differentiation efficacy in vivo of the designed modular cell-laden HOPMs. All the animals were divided into four experimental groups: 1 ) control, ii) blank microspheres in PBS, iii) cells $\left(8 \times 10^{6}\right.$ cells), and iv) cell-laden PLGA HOPMs ( $n=3)$. After 6 weeks of injecting respective samples into each mouse, the newly formed tissues of the marked regions at the injection site were dissected from the sacrificed mice, and tissue volume was calculated by using the formula: volume $(V)=$ (tissue length) $\mathrm{x}$ (tissue width) ${ }^{2} / 2$. In addition, further, analyses relevant to mRNA expressions by PCR and visual observations for cell morphology determination by various staining techniques were performed.

mRNA expressions of different vascular biomarkers including ACE 2, VEGF-A, and angiotensin, were investigated using the qRT-PCR technique. The tissue slices were washed thrice with PBS. The RNA samples were prepared, and then the reverse transcription was performed using the M-MuLV first chain cDNA synthesis kit. The sequences of primers are summarized in Table 4.

Furthermore, various staining methods including H\&E, Masson's trichrome, and Tunel, were used to detect the morphological attributes and apoptotic events in the cells of the newly grown tissues. The tissue samples were sliced, subjected to standard treatments (dewaxing with xylene, hydration with ethanol, and wash with PBS), and then stained with respective dyes and observed under CLSM.

The expressions of respective vascular protein markers were investigated using Western blot method. The proteins were extracted by following the reported procedure. ${ }^{[25]}$ The tissue block was cleaved, and the cells were collected and homogenized using the radioimmunoprecipitation assay (RIPA) buffer. Proteins were separated by SDS 
polyacrylamide gel electrophoresis (SDS-PAGE) and subsequently blotted onto an immunoblot polyvinylidene difluoride (PVDF) membrane (Bio-Rad). The membrane blots were blocked with $5 \%$ non-fat milk in a mixture of Tris-buffered saline $(20 \mathrm{mM}$ Tris- $\mathrm{HCl}$, $\mathrm{pH} 7.4$, and $137-\mathrm{mM} \mathrm{NaCl}$ ) and $0.05 \%$ Tween 20 (TBST) at ambient temperature for $1 \mathrm{~h}$ and incubated with the appropriate primary antibody (ACE 2, angiotensin, VEGF polyclonal antibodies (Proteintech, Rosemont, USA), or GAPDH (Abcam, Cambridge, USA) at $4{ }^{\circ} \mathrm{C}$ overnight. After a wash, the blots were incubated with horseradish peroxidase (HRP)conjugated secondary antibody (ThermoFisher) for $1 \mathrm{~h}$ following TBST washes. Bands were visualized using a Western blot chemiluminescence reagent (Western ECL Substrate, Bio$\mathrm{Rad})$.

\subsection{Statistical analysis}

The data were presented as the mean \pm standard deviation $(n=3)$. All data were compared between groups by analysis of variance (ANOVA) followed by Tukey's honestly significant difference post hoc test at a defined level of statistical significance of $P<0.05$. The data were analyzed using SPSS (Version 18, IBM, Armonk, USA). Minitab software version 17 (Minitab Inc., Pittsburgh, USA) was employed to analyze and optimize the key formulation variables and their significance in the particle fabrication.

\section{Supplementary Material}

Refer to Web version on PubMed Central for supplementary material.

\section{Acknowledgements}

R. K. K. and Z. J. contributed equally to this work. R. K. K., A. Z. C., and S. B. W. acknowledge financial support from National Natural Science Foundation of China (U1605225, 31570974, and 31800794), and Program for Innovative Research Team in Science and Technology in Fujian Province University. Y. S. Z. acknowledges funding provided by the National Institutes of Health (R21EB026175) and the Brigham Research Institute.

\section{References}

[1]. a)Leijten J, Rouwkema J, Zhang YS, Nasajpour A, Dokmeci MR, Khademhosseini A, Small 2016, 12, 2130; [PubMed: 27101419] b)Zhang YS, Arneri A, Bersini S, Shin S-R, Zhu K, GoliMalekabadi Z, Aleman J, Colosi C, Busignani F, Dell'Erba V, Bishop C, Shupe T, Demarchi D, Moretti M, Rasponi M, Dokmeci MR, Atala A, Khademhosseini A, Biomaterials 2016, 110, 45; [PubMed: 27710832] c)Zhang YS, Khademhosseini A, Science 2017, 356;d)Kankala RK, Zhu K, Sun X-N, Liu C-G, Wang S-B, Chen A-Z, ACS Biomater. Sci. Eng 2018, 4, 800;e)Jia W, Gungor-Ozkerim PS, Zhang YS, Yue K, Zhu K, Liu W, Pi Q, Byambaa B, Dokmeci MR, Shin SR, Khademhosseini A, Biomaterials 2016, 106, 58; [PubMed: 27552316] f)Kankala RK, Zhu K, Li J, Wang CS, Wang SB, Chen AZ, Biofabrication 2017, 9, 032002.

[2]. a)Wang L, Cao L, Shansky J, Wang Z, Mooney D, Vandenburgh H, Mol. Ther 2014, 22, 1441; [PubMed: 24769909] b)Kamelger FS, Marksteiner R, Margreiter E, Klima G, Wechselberger G, Hering S, Piza H, Biomaterials 2004, 25, 1649; [PubMed: 14697866] c)Qazi TH, Mooney DJ, Pumberger M, Geißler S, Duda GN, Biomaterials 2015, 53, 502. [PubMed: 25890747]

[3]. a)Bach AD, Beier JP, Stern-Staeter J, Horch RE, J. Cell. Mol. Med 2004, 8, 413; [PubMed: 15601570] b)Vilquin JT, Acta Myol 2005, 24, 119. [PubMed: 16550929]

[4]. a)Nichol JW, Khademhosseini A, Soft Matter 2009, 5, 1312; [PubMed: 20179781] b)Kang SW, Bae YH, Biomaterials 2009, 30, 4227; [PubMed: 19446875] c)Hou Q, Grijpma DW, Feijen J, Biomaterials 2003, 24, 1937; [PubMed: 12615484] d)Li WJ, Tuan RS, Curr. Protoc. Cell Biol 2009, Chapter 25, Unit 25.2; e)Thevenot P, Nair A, Dey J, Yang J, Tang L, Tissue Eng. Part C 
2008, 14, 319;f)Kankala RK, Zhang YS, Wang SB, Lee CH, Chen AZ, Adv Healthc. Mater 2017, 6;g)Takahashi H, Okano T, Adv Healthc. Mater 2016, 4, 2388;h)Khademhosseini A, Langer R, Biomaterials 2007, 28, 5087; [PubMed: 17707502] i)Han J, Kim B, Shin J-Y, Ryu S, Noh M, Woo J, Park J-S, Lee Y, Lee N, Hyeon T, Choi D, Kim B-S, ACS Nano 2015, 9, 2805; [PubMed: 25688594] j)Choi S-W, Zhang Y, Yeh Y-C, Wooten A. Lake, Xia Y, J. Mater. Chem 2012, 22, 11442;k)Narayan R, Agarwal T, Mishra D, Maji S, Mohanty S, Mukhopadhyay A, Maiti TK, Colloids and Surfaces B: Biointerfaces 2017, 160, 661; [PubMed: 29031226] 1)Jordahl JH, Solorio L, Sun H, Ramcharan S, Teeple CB, Haley HR, Lee KJ, Eyster TW, Luker GD, Krebsbach PH, Lahann J, Adv. Mater 2018, 30, 1707196;m)Sheng Z-Z, Liu X, Min L-L, Wang H-L, Liu W, Wang M, Huang L-Z, Wu F, Hou X, Chin. Chem. Lett 2017, $28,1131$.

[5]. a)Choi YS, Park S-N, Suh H, Biomaterials 2005, 26, 5855; [PubMed: 15949551] b)Hou X, Zhang YS, Santiago G. T.-d., Alvarez MM, Ribas J, Jonas SJ, Weiss PS, Andrews AM, Aizenberg J, Khademhosseini A, Nat. Rev. Mater 2017, 2, 17016.

[6]. a)Mei Y, Luo H, Tang Q, Ye Z, Zhou Y, Tan W-S, J. Biotechnol 2010, 150, 438; [PubMed: 20888876] b)Wang C, Gong Y, Zhong Y, Yao Y, Su K, Wang D-A, Biomaterials 2009, 30, 2259; [PubMed: 19152973] c)Lao L, Tan H, Wang Y, Gao C, Colloids Surface. B 2008, 66, 218;d)Matsunaga YT, Morimoto Y, Takeuchi S, Adv. Mater 2011, 23, H90. [PubMed: 21360782]

[7]. a)Chung HJ, Park TG, Tissue Eng. Part A 2009, 15, 1391; [PubMed: 19327016] b)Kim TK, Yoon JJ, Lee DS, Park TG, Biomaterials 2006, 27, 152; [PubMed: 16023197] c)Chung HJ, Kim IK, Kim TG, Park TG, Tissue Eng. Part A 2008, 14, 607; [PubMed: 18361764] d)Lim SM, Lee HJ, Oh SH, Kim JM, Lee JH, J. Biomed. Mater. Res. B 2009, 90B, 521;e)Wei D-X, Dao J-W, Chen G-Q, Adv. Mater 2018, 30, 1802273;f)Li R, Chen K, Li G, Han G, Yu S, Yao J, Cai Y, J. Mol. Struct 2016, 1120, 34;g)Mao Z, Fang Z, Yang Y, Chen X, Wang Y, Kang J, Qu X, Yuan W, Dai K, RSC Adv 2017, 7, 24607;h)Zhang Z, Eyster TW, Ma PX, Nanomedicine (Lond) 2016, 11 , 1611; [PubMed: 27230960] i)Kuang R, Zhang Z, Jin X, Hu J, Gupte MJ, Ni L, Ma PX, Adv Healthc. Mater 2015, 4, 1993; [PubMed: 26138254] j)Ma T, Zhang YS, Chen A-Z, Ju J, Gu C-W, Kankala RK, Wang S-B, J. Supercrit. Fluid 2017, 120, 43.

[8]. a)Choi S-W, Yeh Y-C, Zhang Y, Sung H-W, Xia Y, Small 2010, 6, 1492; [PubMed: 20578116] b)Huang C-C, Wei H-J, Yeh Y-C, Wang J-J, Lin W-W, Lee T-Y, Hwang S-M, Choi S-W, Xia Y, Chang Y, Sung H-W, Biomaterials 2012, 33, 4069. [PubMed: 22386922]

[9]. Choi S-W, Zhang Y, Xia Y, Langmuir 2010, 26, 19001. [PubMed: 21090781]

[10]. a)Sciote JJ, Morris TJ, J. Orthod 2000, 27, 15; [PubMed: 10790441] b)Gillies AR, Lieber RL, Muscle Nerve 2011, 44, 318; [PubMed: 21949456] c)Smith AST, Shah R, Hunt NP, Lewis MP, Semin. Orthod 2010, 16, 135;d)Fortin M, Videman T, Gibbons LE, Battié MC, Med. Sci. Sports Exerc 2014, 46, 893. [PubMed: 24091994]

[11]. a)Relaix F, Zammit PS, Development 2012, 139, 2845; [PubMed: 22833472] b)Hikida RS, Curr. Aging Sci 2011, 4, 279; [PubMed: 21529324] c)Macaluso F, Myburgh KH, J. Muscle Res. Cell Motil 2012, 33, 187. [PubMed: 22673936]

[12]. a)Riboldi SA, Sampaolesi M, Neuenschwander P, Cossu G, Mantero S, Biomaterials 2005, 26, 4606; [PubMed: 15722130] b)Kwiecien GJ, Lamaris G, Gharb BB, Murray T, Hendrickson MF, Zins JE, Isakov R, Plast. Reconstr. Surg 2016, 137, 177e;c)Schaverien MV, Hart AM, Hand Clin 2014, 30, 165; [PubMed: 24731608] d)C. CA, O. I, Z. PS, H. L, P. A, P. TA, M. JE, Cell 2005, 122, 289; [PubMed: 16051152] e)Ferrari G, Cusella-De AG, Coletta M, Paolucci E, Stornaiuolo A, Cossu G, Mavilio F, Science 1998, 279, 1528; [PubMed: 9488650] f)Partridge TA, Morgan JE, Coulton GR, Hoffman EP, Kunkel LM, Nature 1989, 337, 176; [PubMed: 2643055] g)Skuk D, Roy B, Goulet M, Chapdelaine P, Bouchard JP, Roy R, Dugré FJ, Lachance JG, Deschênes L, Hélène S, Mol. Ther 2004, 9, 475; [PubMed: 15038390] h)Darabi R, Pan W, Bosnakovski D, Baik J, Kyba M, Perlingeiro RC, Stem Cell Reviews and Reports 2011, 7, 948;i)Darabi R, Gehlbach K, Bachoo RM, Kamath S, Osawa M, Kamm KE, Kyba M, Perlingeiro RC, Nat. Med 2008, 14, 134; [PubMed: 18204461] j)Zheng, Wang, Aditi, Karandikar, Qian, Wang, Lian, Chao, Peng, Zhen, Cell Res 2006, 16, 713; [PubMed: 16788572] k)Mertens JP, Sugg KB, Lee JD, Larkin LM, Regen. Med 2014, 9, 89. [PubMed: 24351009]

[13]. a)Frey L, Bandaru P, Zhang YS, O'Kelly K, Khademhosseini A, Shin SR, Adv. Funct. Mater 2018, 28, 1702009;b)Nejad H. Rezaei, Malekabadi Z. Goli, Narbat M. Kazemzadeh, Annabi N, Mostafalu P, Tarlan F, Zhang YS, Hoorfar M, Tamayol A, Khademhosseini A, Small 2016, 12, 5132; [PubMed: 27510763] c)Riahi R, Shaegh SAM, Ghaderi M, Zhang YS, Shin SR, Aleman J, 
Massa S, Kim D, Dokmeci MR, Khademhosseini A, Sci. Rep 2016, 6, 24598. [PubMed: 27098564]

[14]. Rangarajan S, Madden L, Bursac N, Ann. Biomed. Eng 2014, 42, 1391. [PubMed: 24366526]

[15]. Huang CC, Wei HJ, Yeh YC, Wang JJ, Lin WW, Lee TY, Hwang SM, Choi SW, Xia Y, Chang Y, Biomaterials 2012, 33, 4069. [PubMed: 22386922]

[16]. Tsao CT, Chang CH, Lin YY, Wu MF, Wang JL, Han JL, Hsieh KH, Carbohydr. Res 2010, 345, 1774. [PubMed: 20598293]

[17]. a)Kalia P, Brooks RA, Kinrade SD, Morgan DJ, Brown AP, Rushton N, Jugdaohsingh R, PLoS One 2016, 11, e0144780; [PubMed: 26863624] b)Chen BQ, Kankala RK, Chen AZ, Yang DZ, Cheng XX, Jiang NN, Zhu K, Wang SB, Int J Nanomedicine 2017, 12, 1877. [PubMed: 28331312]

[18]. Lin X, Yang H, Su L, Yang Z, Tang X, J. Drug Deliv. Sci. Technol 2018, 45, 346.

[19]. a)Wolf MT, Dearth CL, Sonnenberg SB, Loboa EG, Badylak SF, Adv. Drug Deliv. Rev 2015, 84, 208; [PubMed: 25174309] b)Son JS, Lee KB, Kim SG, Kwon TY, Kim KH, Mater. Lett 2012, 76, 243 ;c)Wang PY, Wu TH, Tsai WB, Kuo WH, Wang MJ, Colloids Surface. B 2013, 110, 88.

[20]. a)Mura S, Hillaireau H, Nicolas J, Le Droumaguet B, Gueutin C, Zanna S, Tsapis N, Fattal E, Int. J. Nanomedicine 2011, 6, 2591; [PubMed: 22114491] b)Kang Y, Wu J, Yin G, Huang Z, Yao Y, Liao X, Chen A, Pu X, Liao L, Eur. J. Pharm. Biopharm 2008, 70, 85. [PubMed: 18495445]

[21]. Cadée JA, Brouwer LA, Den OW, Hennink WE, M. J. van Luyn, J. Biomed. Mater. Res 2015, 56, 600.

[22]. a)Melero-Martin JM, Dowling MA, Smith M, Al-Rubeai M, Biomaterials 2006, 27, 2970; [PubMed: 16455134] b)Webb K, Hlady V, Tresco PA, J. Biomed. Mater. Res 1998, 41, 422; [PubMed: 9659612] c)Boukari Y, Scurr DJ, Qutachi O, Morris AP, Doughty SW, Rahman CV, Billa N, J. Biomater. Sci. Polym. Ed 2015, 26, 796; [PubMed: 26065672] d)Liu Y, Liang X, Wang S, Hu K, J. Biomater. Tissue Eng 2016, 6, 719;e)Liu M, Yang J, Hu W, Zhang S, Wang Y, Biomed Mater 2016, 11, 015008;f)Zhan J, Liu J, Wang C, Fan C, Ei-Hamshary HA, Al-Deyab SS, Mo X, J. Bioact. Compat. Polym 2015, 31;g)C. S, T. C, D. A, L. J, B. G, E. A, H. A, E. T, V. C, C. C, PLoS One 2012, 7, e36173. [PubMed: 22558372]

[23]. a)Berenzi A, Steimberg N, Boniotti J, Mazzoleni G, Microsc. Res. Tech 2015, 78, 249; [PubMed: 25639567] b)Rangarajan S, Madden L, Bursac N, Ann. Biomed. Eng 2014, 42, 1391. [PubMed: 24366526]

[24]. Bueno EM, Bilgen B, Barabino GA, Tissue Eng 2015, 11, 1699.

[25]. Kankala RK, Kuthati Y, Liu C-L, Mou C-Y, Lee C-H, RSC Adv 2015, 5, 86072. 


\section{Fabrication of HOPMs}
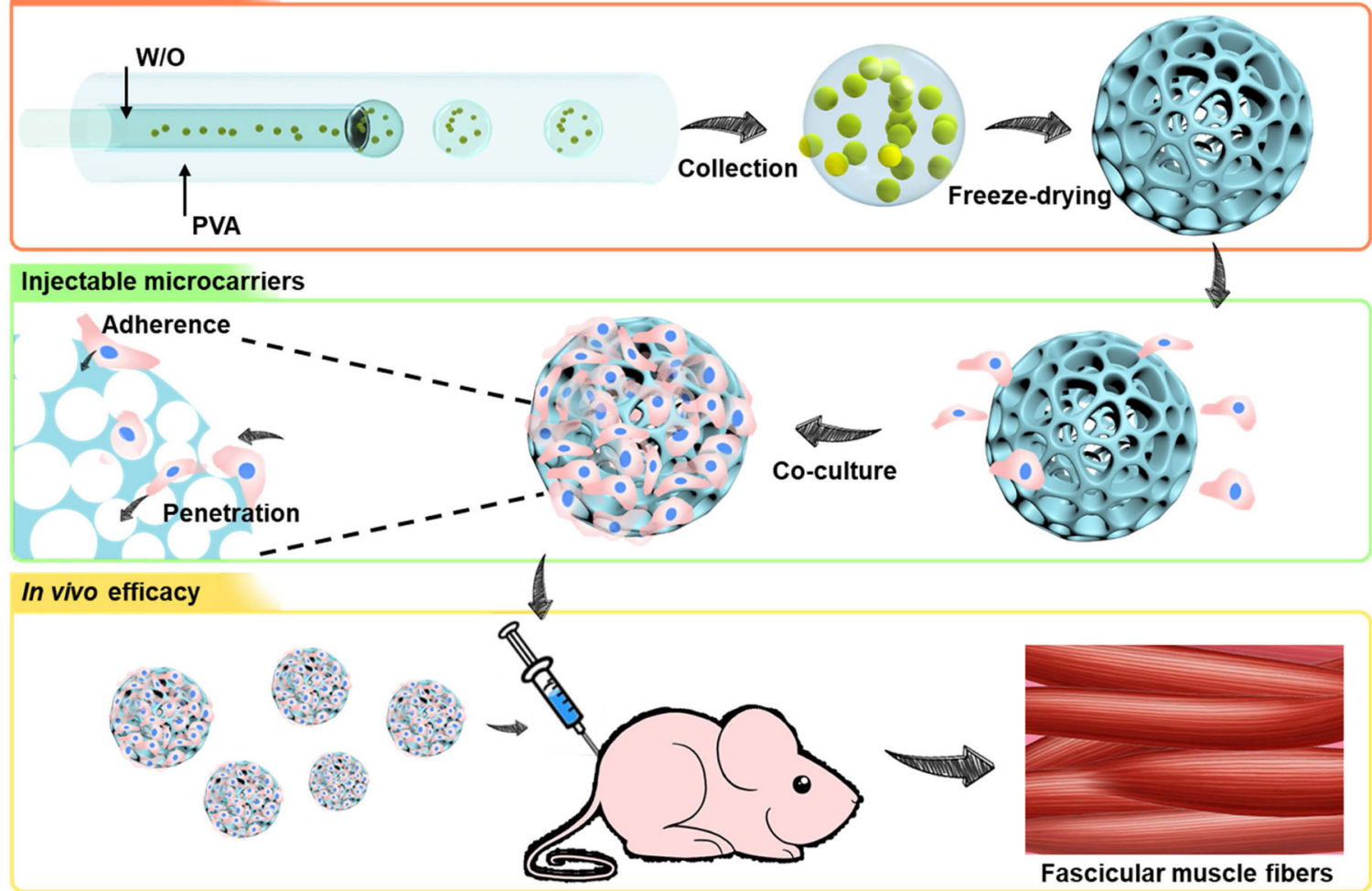

Figure 1. Overview of the study.

Schematic illustration showing the generation of PLGA HOPMs by microfluidic technology, fabrication of modular cell-laden HOPMs by populating the $\mathrm{C} 2 \mathrm{C} 12$ cells on the microcarriers in vitro, and evaluating their performance in vivo after administering these cell-laden HOPMs in nude mice. 

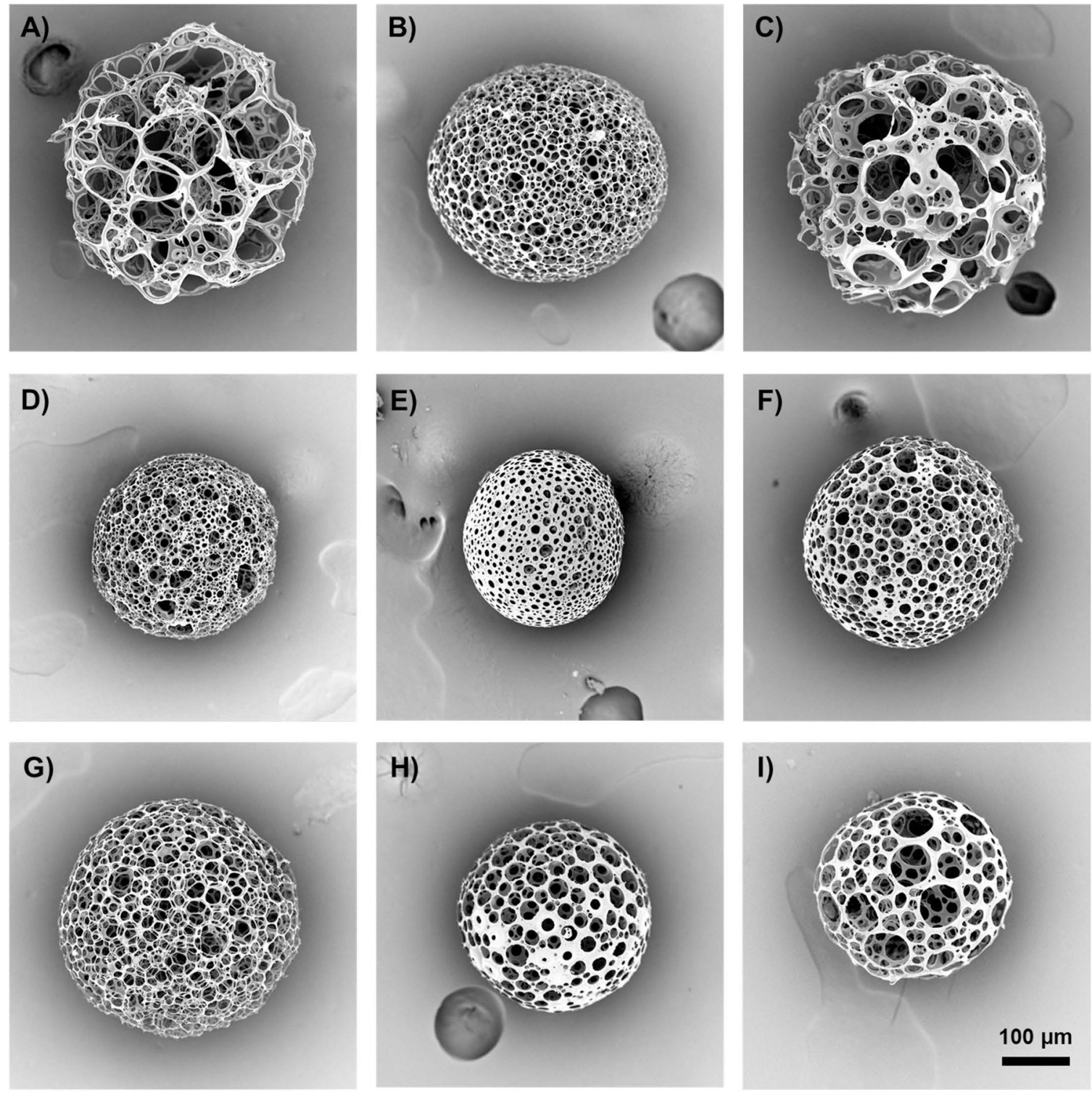

Figure 2.

SEM images of PLGA HOPMs prepared at different experimental conditions based on the Minitab full factorial design run order as shown in Table 1 (A: run-1; B: run-2; C: run-3; D: run-4; E: run-5; F: run-6; G: run-7; H: run-8; I: run-9). 
A)

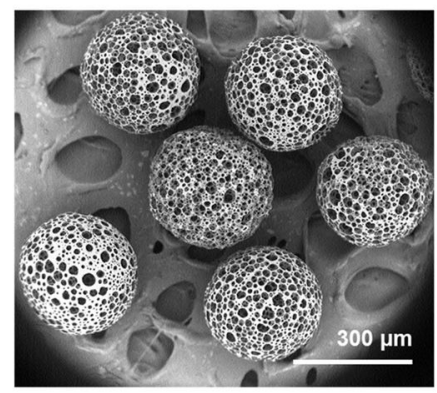

D)

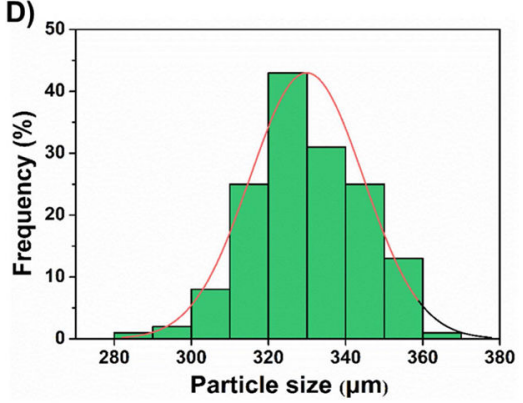

B)

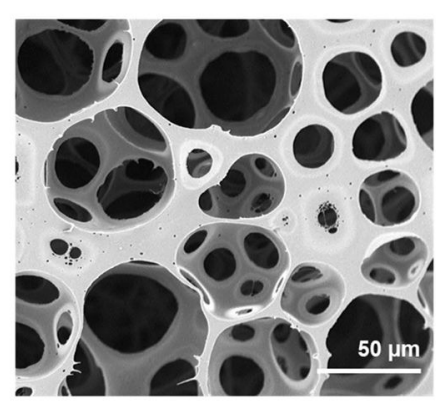

E)

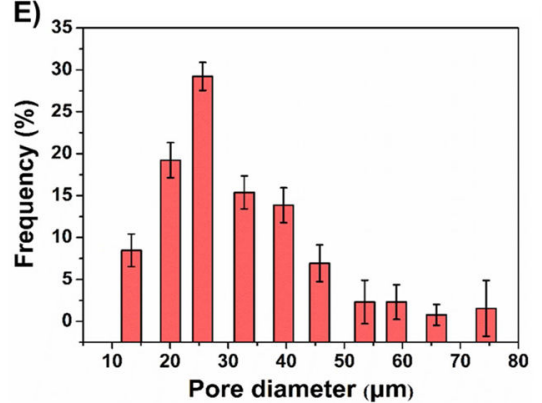

C)

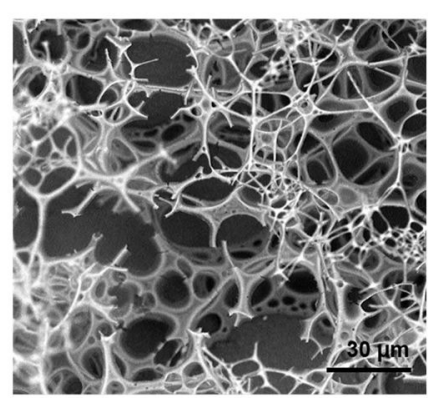

F)

i)

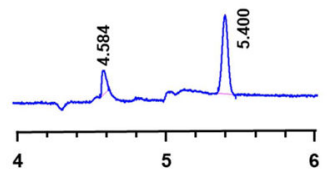

ii)

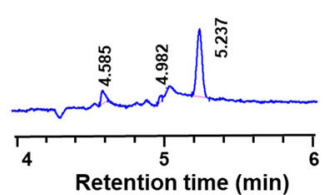

Figure 3. Physical characterization of PLGA HOPMs.

A-C) SEM images showing A) size distribution of PLGA HOPMs, B) surface morphology of a microcarrier, and $\mathbf{C}$ ) cross-sectional view displaying the interior of a microcarrier. D-E) Frequency analyses illustrating D) the particle size distribution (average pore size: $320 \mu \mathrm{m}$ ) as well as $\mathbf{E}$ ) the pore diameter distribution (distributed in the range of 10-80 $\mu \mathrm{m}$ ) of fabricated PLGA HOPMs (obtained at the optimal conditions based on run-9 of Table 1), based on the SEM image (Figure B) analysis $(n=200)$. F) Gas chromatographic analysis showing the organic solvent (DCM) residue in the PLGA HOPMs at a retention time $\left(t_{R}\right)$ of 5.4 min for (i) DCM and (ii) PLGA HOPMs. 
A)
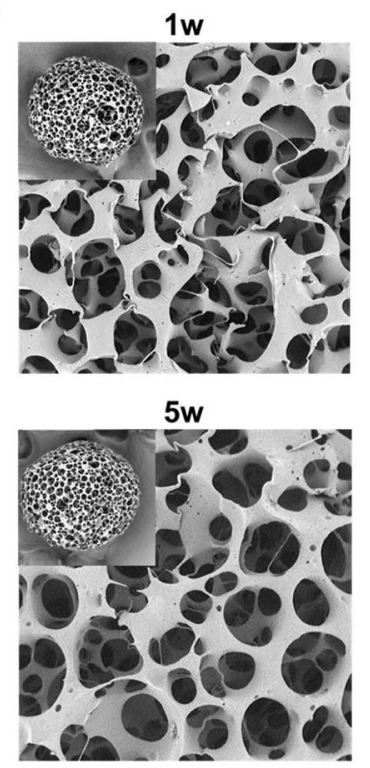

B)

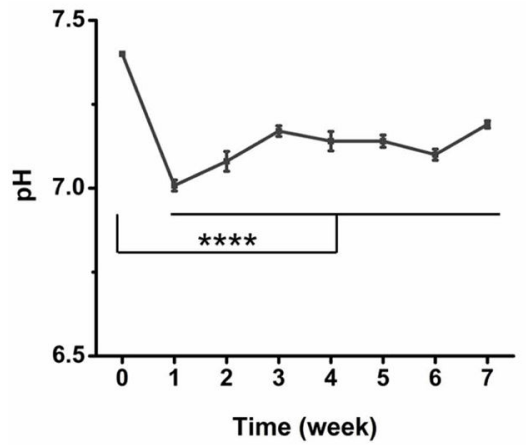

$2 w$

$6 w$
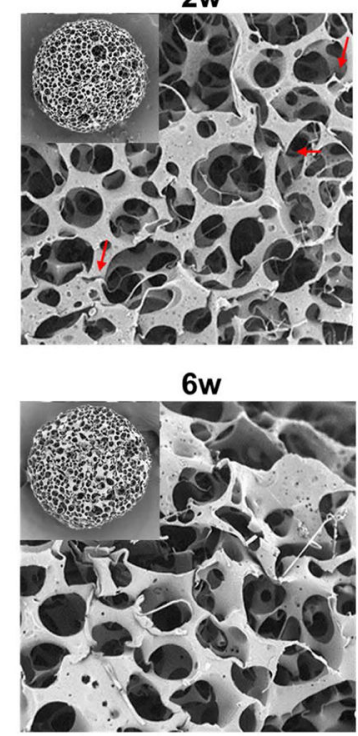

C)

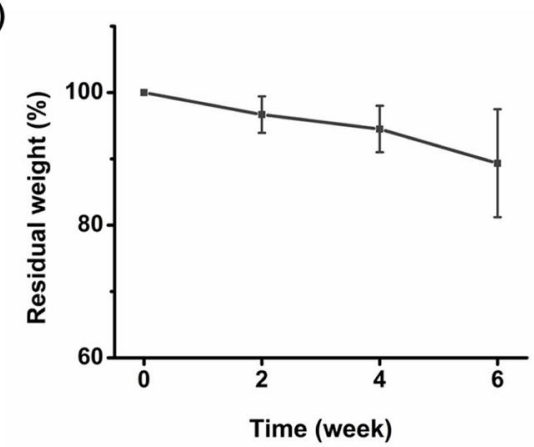

Figure 4. Degradation analysis in vitro of PLGA HOPMs in PBS (pH-7.4, replenished every week) for a 7-week incubation period.

A) SEM images showing the degraded surfaces of microcarriers over the analysis period (inset showing the respective complete microcarrier, arrows indicating the fragmented interconnecting windows). Graphical representation illustrating the changes in $\mathbf{B}$ ) the $\mathrm{pH}$ value of the buffer and $\mathbf{C}$ ) the residual mass of PLGA HOPMs. ****P $<0.0001$ 
A)
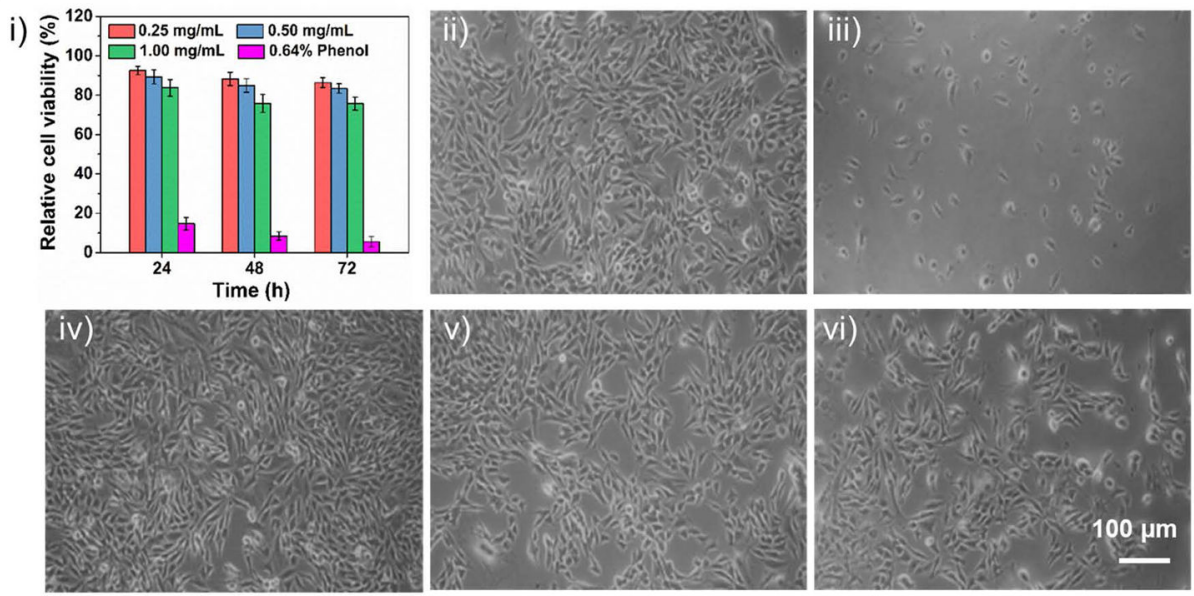

B)

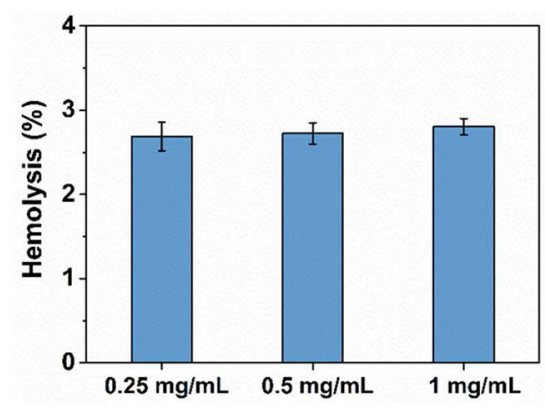

C)

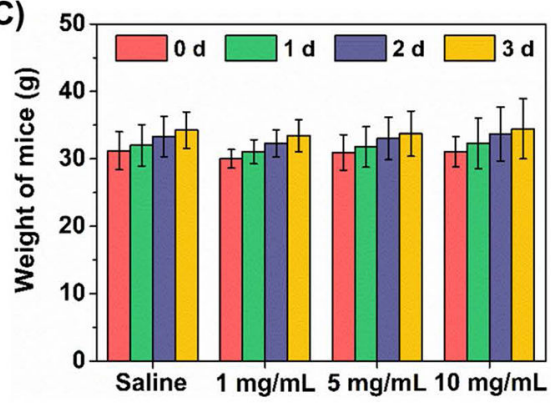

D)

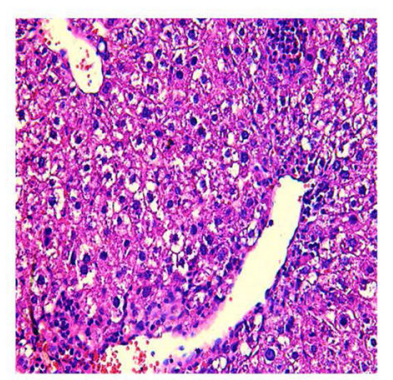

Experimental group

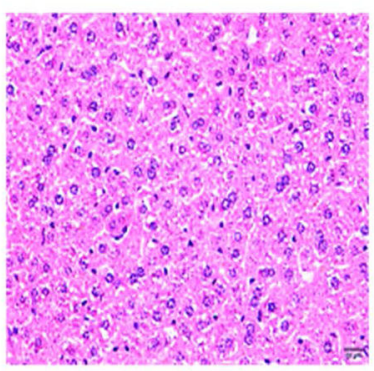

Negative control

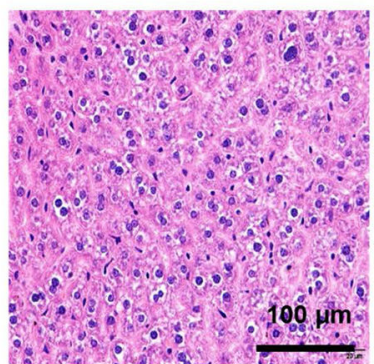

Figure 5. Biocompatibility investigations of PLGA HOPMs.

A) i) In vitro cytotoxicity test showing the viability of $\mathrm{C} 2 \mathrm{C} 12$ cells after treatment with various concentrations of PLGA HOPMs and positive control ( $0.64 \%$ of phenol in medium) at different exposure times relative to negative control, presumed as viability of $100 \%$; results are shown as mean \pm SDs of six parallel samples. Corresponding microscopic images of cells captured after treatment for $72 \mathrm{~h}$ : ii) negative control (no treatment), iii) positive control, and iv-vi) $0.25,0.5$, and $1 \mathrm{mg} / \mathrm{mL}$ of PLGA HOPMs. B) Hemolysis rates of rabbit blood after treatment with various concentrations of PLGA HOPMs. C) Body weight changes observed after intraperitoneal injection of PLGA HOPMs in KM mice $(n=10)$ along with negative control (saline) and positive control (6.4\% phenol). For positive control, weights were not recorded as all the animals were dead. D) H\&E-stained liver sections from mice treated with PLGA HOPMs for observing pathological changes. 
A)
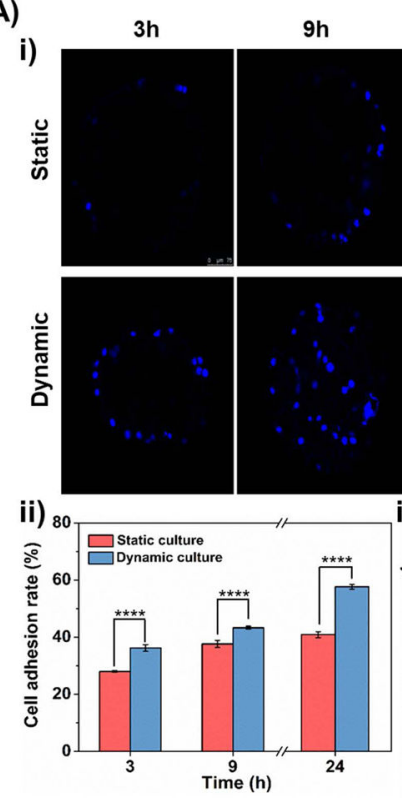

D)

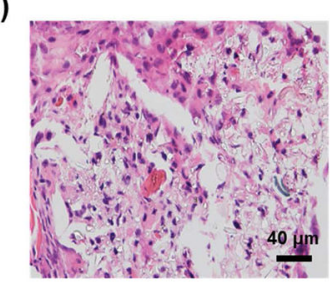

B)
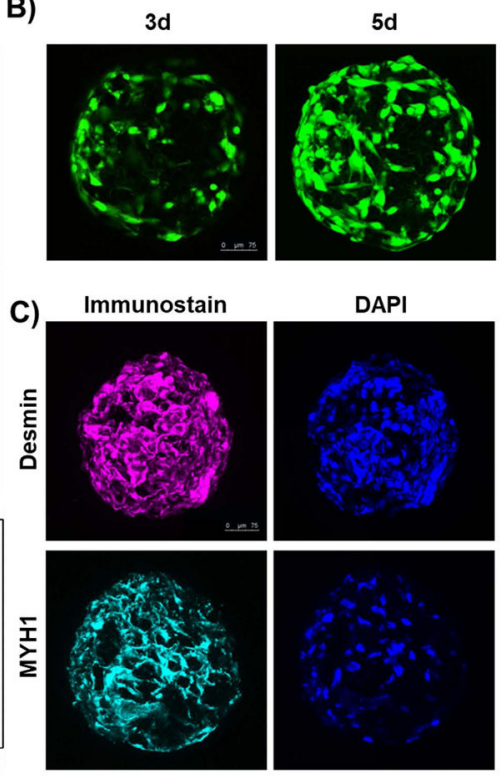

E)

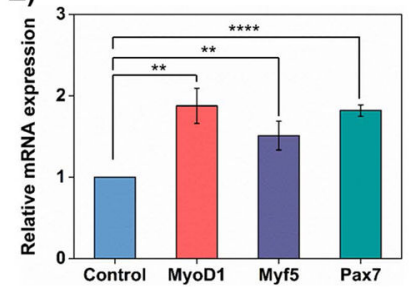

Figure 6. Construction of cell-laden PLGA HOPMs in vitro.

A) i) CLSM images showing the time-dependent growth of myoblasts cultured in the PLGA HOPMs for various time periods (3, 9, 24, and 48 h). ii, iii) Graphical representations showing ii) adhesion of the cells $(3,9$, and $24 \mathrm{~h})$ as well as iii) the number of myoblasts, under static and dynamic cultures. B) CLSM images showing the proliferation of myoblasts on the PLGA HOPMs for 12 days. C) Immunohistological analysis of myoblasts in the PLGA HOPMs by staining them against desmin and MYH1 (counterstained by DAPI for nuclei) for 7 days. D) H\&E staining of myoblasts in the PLGA HOPMs. E) Gene expression profiles of myoblasts in the PLGA HOPMs (MyoD1, Myf 5, and Pax 7). **P 0.01, $* * * * \mathrm{P}<0.0001$. 
A)
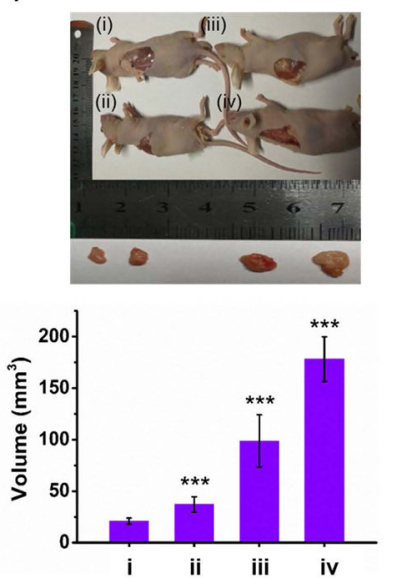

E)

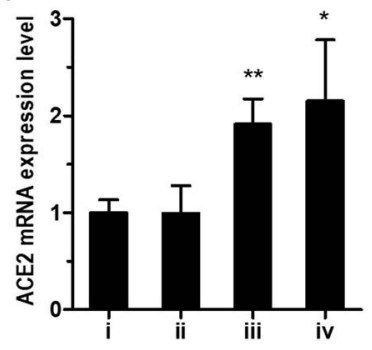

B)
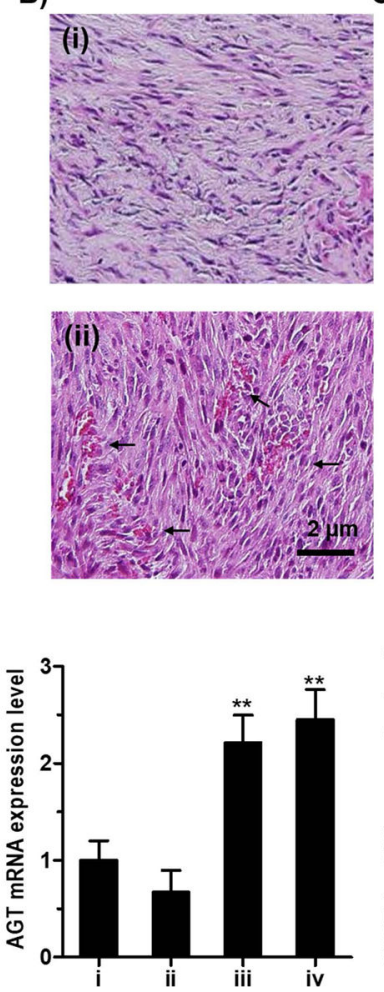

C)
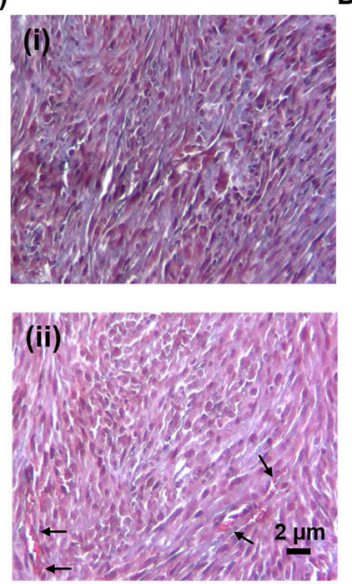

D)
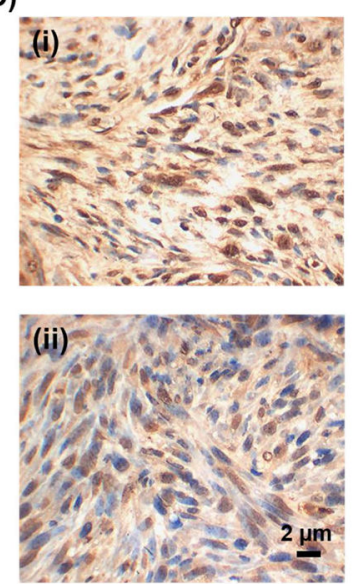

F)

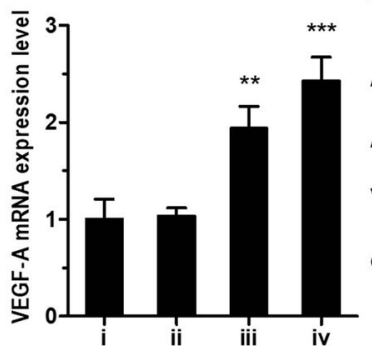

Figure 7. In vivo efficacy of cells-laden PLGA HOPMs.

A) Images showing the growth of myoblasts in mice ( $n=3$ per group) treated with various samples (i) control (normal saline), (ii) microcarriers (suspended in PBS) (iii) isolated cells $\left(8 \times 10^{6} / \mathrm{mL}\right.$ suspended in PBS), and (iv) cells-laden PLGA HOPMs (suspended in PBS) along with the calculated volumes of the isolated tissues. $* * * \mathrm{P}<0.001$. B) H\&E staining, C) Masson staining, and D) Tunel assay, of the explanted tissues from the mice after 6 weeks of treatment (i) isolated cells $\left(8 \times 10^{6} / \mathrm{mL}\right.$ suspended in PBS), and (ii) cells-laden PLGA HOPMs (suspended in PBS). E) Gene expressions (ACE 2, AGT refers to angiotensin and VEGF-A; 18S ribosomal RNA (rRNA)-calibrated) profiles by qRT-PCR, for determining the vascularization potential of the newly formed tissues. $* \mathrm{P}<0.05$, $* * \mathrm{P}<0.01, * * * \mathrm{P}<0.001$. F) Expressions of vascular biomarkers (ACE 2, AGT refers to angiotensin, VEGF-A, and GAPDH) determined by Western blot analysis (sample indications (i-iv) in $\mathbf{E}$ and $\mathbf{F}$ are similar to those denoted in $\mathbf{A}$ ). 
A)
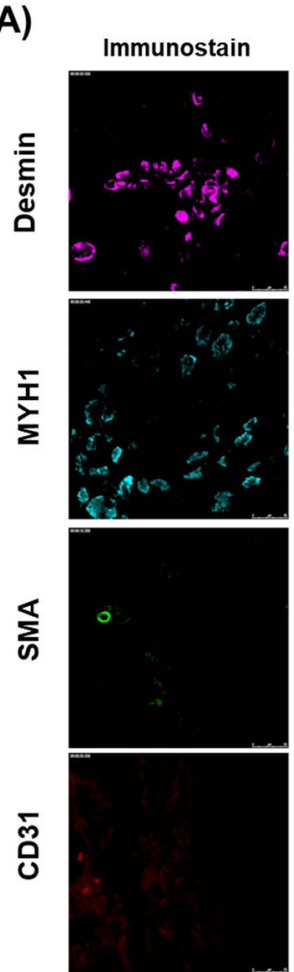
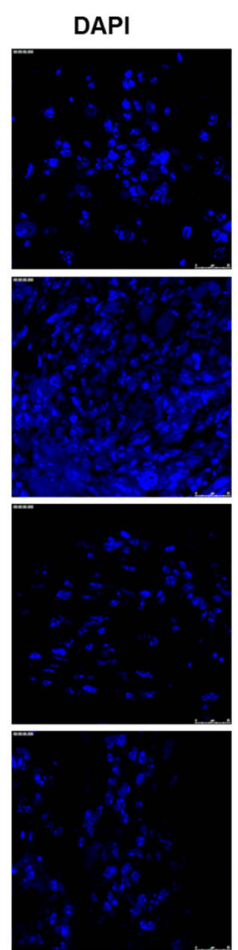

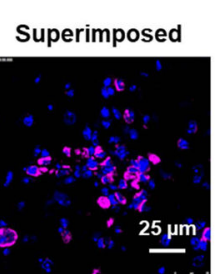

B)
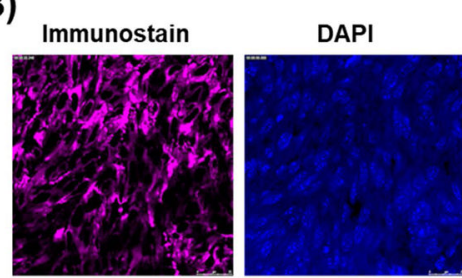

Superimposed
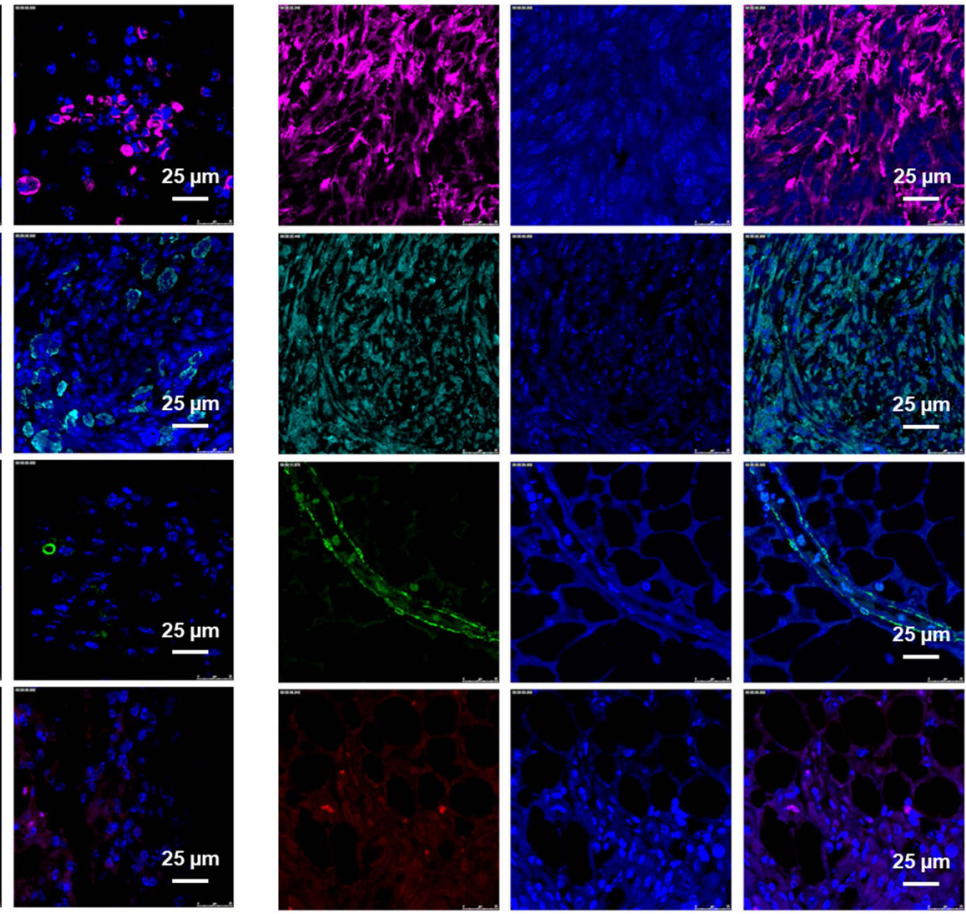

Figure 8. Immunohistochemical analysis of PLGA HOPMs.

Immunohistochemical staining of myoblast-specific (desmin, MYH1) and vascular specific (SMA, CD31) markers, in A) blank group (HOPMs alone) and B) cell-laden PLGA HOPMs treatment group. The nuclei were counterstained with DAPI. 
Table 1.

Experimental results based on the run orders of Minitab full-factorial design.

\begin{tabular}{cccccccc}
\hline Run order & Center Pt & Blocks & $\mathbf{A}^{\boldsymbol{a}}$ & $\mathbf{B}^{\boldsymbol{a}}$ & $\mathbf{C}^{\boldsymbol{a}}$ & Particle size $(\boldsymbol{\mu m})^{\boldsymbol{b}}$ & Pore diameter $(\boldsymbol{\mu m}) \boldsymbol{b}^{\boldsymbol{b}}$ \\
\hline 1 & 1 & 1 & 1 & -1 & -1 & $351.44 \pm 10.03$ & $18.21 \pm 4.67$ \\
2 & 1 & 1 & -1 & 1 & -1 & $269.35 \pm 24.03$ & $13.66 \pm 4.13$ \\
3 & 1 & 1 & 1 & 1 & -1 & $397.33 \pm 10.81$ & $31.06 \pm 1.65$ \\
4 & 1 & 1 & 1 & -1 & 1 & $332.86 \pm 20.24$ & $12.01 \pm 2.41$ \\
5 & 1 & 1 & -1 & 1 & 1 & $276.30 \pm 10.35$ & $8.43 \pm 0.66$ \\
6 & 1 & 1 & 1 & 1 & 1 & $293.22 \pm 11.22$ & $19.22 \pm 4.84$ \\
7 & 1 & 1 & -1 & -1 & 1 & $367.83 \pm 16.36$ & $22.32 \pm 1.61$ \\
8 & 1 & 1 & -1 & -1 & -1 & $395.27 \pm 18.18$ & $32.76 \pm 3.50$ \\
$9^{c}$ & 1 & 1 & 0 & 0 & 0 & $322.10 \pm 11.29$ & $31.28 \pm 5.75$ \\
$10^{c}$ & 1 & 1 & 0 & 0 & 0 & $314.44 \pm 14.52$ & $30.19 \pm 4.97$ \\
$11^{c}$ & 1 & 1 & 0 & 0 & 0 & $325.97 \pm 15.03$ & $29.18 \pm 4.80$ \\
\hline
\end{tabular}

${ }^{a}$ Corresponding values representing the given codes are presented in Table 2

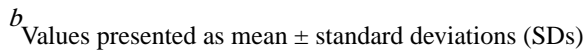

${ }^{c}$ Corresponding combinations of fabrication parameters are presented in Table S1 and Figure S2 (9: A-ii, 10: B-ii, 11: C-ii). 
Table 2.

Various formulation parameters and levels of Minitab design.

\begin{tabular}{lcccc}
\hline Level & Code & A Gelatin concentration (\%) & B W/O (v/v) & C PLGA concentration (\%) \\
\hline High level & 1 & 8.5 & $1 / 3.2$ & 2.5 \\
Medium level & 0 & 7.5 & $1 / 2.4$ & 2.0 \\
Low level & -1 & 6.5 & $1 / 1.6$ & 1.5 \\
\hline
\end{tabular}


Table 3.

Sequences of primers used for qRT-PCR analysis of myoblast-specific gene expressions.

\begin{tabular}{lll}
\hline Primer name & Orientation & \multicolumn{1}{c}{ Sequence (5'-3') } \\
\hline MyoD1 & Forward & ACTGCTCTGATGGCATGATGGATTAC \\
& Reverse & ACTGTAGTAGGCGGTGTCGTAGC \\
\multirow{2}{*}{ Myf5 } & Forward & GACGCCTGAAGAAGGTCAACCAAG \\
& Reverse & GGCTGTAATAGTTCTCCACCTGTTCC \\
Pax7 & Forward & GCCGCCTTCAACCACCTTCTG \\
& Reverse & GTGTACTGTGCTGCCTCCATCTTG \\
\hline
\end{tabular}


Table 4.

Sequences of primers used for qRT-PCR analysis of vascular-specific gene expressions.

\begin{tabular}{lll}
\hline Primer name & Orientation & \multicolumn{1}{c}{ Sequence (5'-3') } \\
\hline ACE 2 & Forward & TACTGAAGAAAATGCCCAAAAGAT \\
& Reverse & TTTGCTGAAGGGCCTGTAGTT \\
\multirow{2}{*}{ VEGF-A } & Forward & GCACCCACGACAGAAGGA \\
& Reverse & CAATCGGACGGCAGTAGCAGT \\
\multirow{2}{*}{ Angiotensin } & Forward & CAACCCCCGAGTGGGAGAG \\
& Reverse & TCGTAGATGGCGAACAGGAAG \\
\hline
\end{tabular}

